\title{
أسباب ضعف الطلبة في مهارات اللغة العربية في ضوء نتائج الاختبار الوطني 2019 وطرق علاجها
}

\author{
عفاف راضي علي هواري

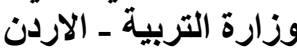

البريد الاكتروني: hwareafaf@gmail.com

هدفت الدراسة إلى الوقوف على اسباب ضعف الطلبة في مهارات اللغة العربية وطرق علاجها، وقد اثتمل مجتمع الدر اسة على معلمي ومعلمات المدارس الحكومية العاملين في مديرية التربية والتعليم في لواءي الطيبة و الوسطية، إذ تم اختيار عينة الدراسة عن طريق المنهج الوصفي المسحي ، وتكونت عينة الدر اسة من (100) معلما ومعلمة ، هذا واستخدمت الدر اسة الاستبيان كأداة للار اسة للوصول الى الأهداف حيث تم تطوير ها للكثف عن أسباب ضعف الطلبة في مهارات اللغة العربية ، أظهرت النتائج أن أسباب ضعف الطلبة في مهار ات اللغة

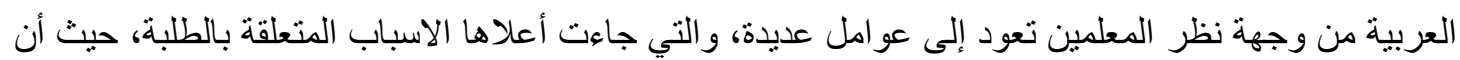
هناك فروقاً فردية بين الطلبة، وأن هناك ضعفاً لدى المعلمين في تلبية حاجات الطلبة ووضع الخطط العلاجية و الخطط الفردي لذوي الاحتياجات الاضافية من الطلبة في مادة اللغة العربية كما يمكن عزو هذه النتيجة ايضاً ربما لتعرض الطلبة لبعض المشاكل الاجتماعية او الاكاديمية التي يمكن أن تؤثر على تحصيلهم العلمي وخاصة في مادة اللغة العربية ، وقد استخدم البرنامج الاحصائي (spss) لمعالجة البيانات إحصائياً واستخر اج النتائج. 


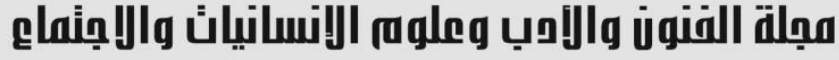

Journal of Arts, Literature, Humanities and Social Sciences

www.jalhss.com

Volume (61) November 2020 [ العدد (61) نوفمبر 2020 ALSS

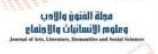

$=-$

\title{
Reasons for students weakness in Arabic language skills in light of the national test 2019 and methods of treatment
}

\author{
Afaf Radi Hawari \\ Ministry of Education - Jordan \\ Email: hwareafaf@gmail.com
}

\begin{abstract}
The study aimed to find out the reasons for students weakness in Arabic language skills and methods of treatment and the study community included male and female teachers of government schools working in the Directorate of Education in the Taybeh and Wastia Brigades. The study sample was chosen by the descriptive survey method and the study sample consisted of 100 male and female teachers . The study used the questionnaire as a study tool tp reach the goals, as it was developed to reveal the reasons for students weakness in Arabic language skills. The results showed that the reasons for students weakness in the Arabic language skills from the teachers point of view are due to many factors, the highest reasons are related to students, as there are individual differences between students. And there are weakness among teachers in meeting the needs of students and setting treatment plans for those with additional needs of students in the Arabic language subject . It can also be attributed to this result, perhaps because students are exposed to some social and academic problems that may affect their academic preparation, especially in the Arabic language subject . The statistical program ( spss ) was used to statistically process the data and extract the results .
\end{abstract}

Keywords: Skill, Arabic language skills, National test. 


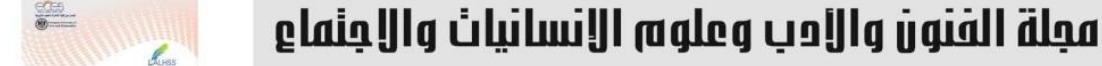

Journal of Arts, Literature, Humanities and Social Sciences www.jalhss.com

Volume (61) November 2020
العدد (61) نوفمبر 2020 - 20

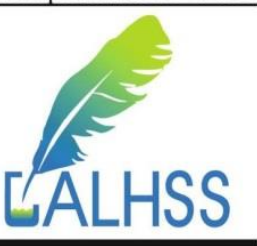

المقدمة

بسم الله الرحمن الرحيم و الصلاة و السلام على الهادي الامين الذي أخرج الناس من الظلمات إلى النور ،

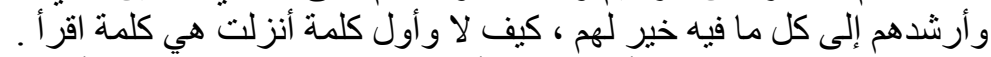

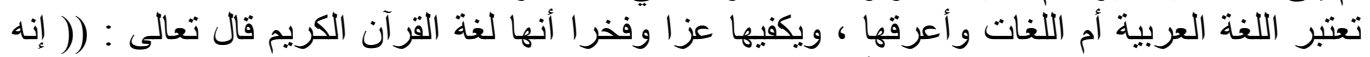

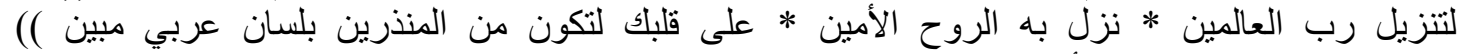

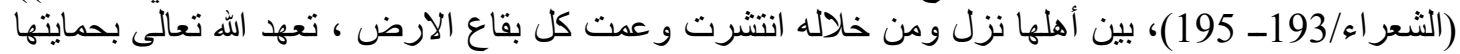

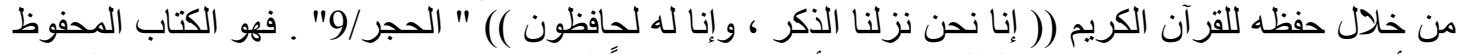

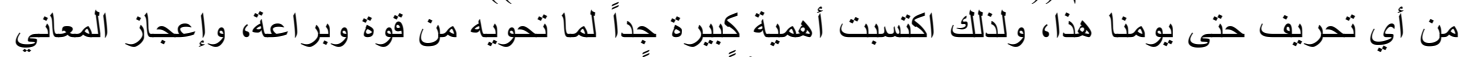

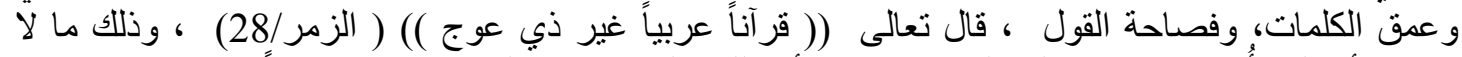

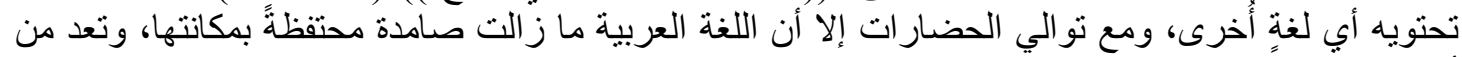

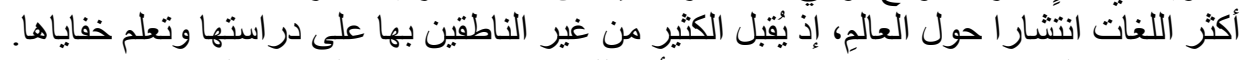

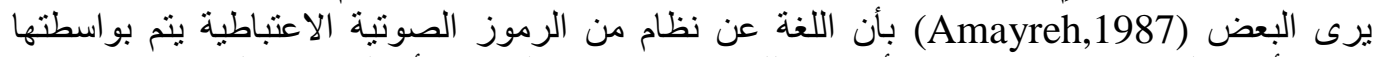

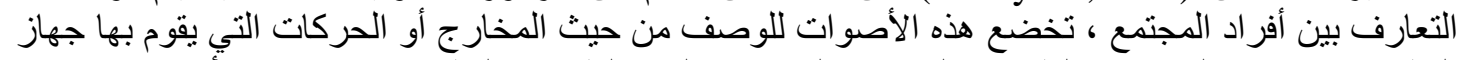

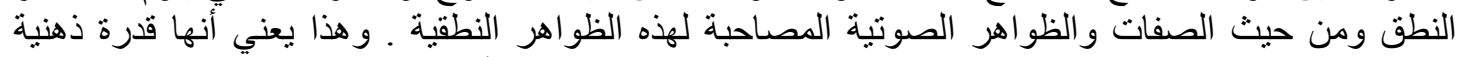

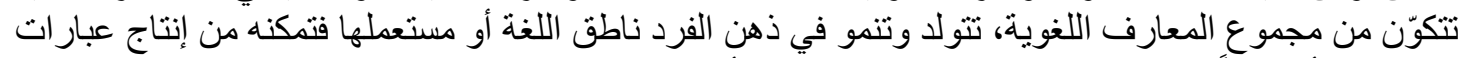

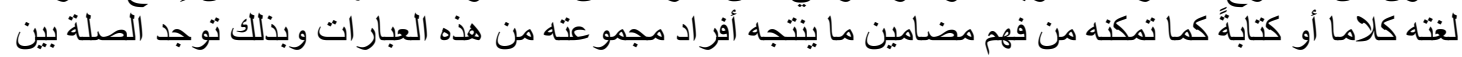

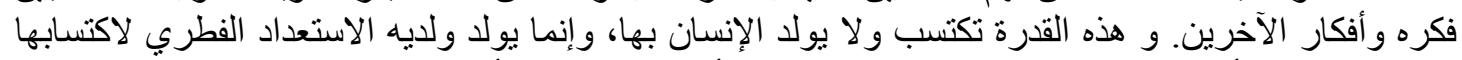

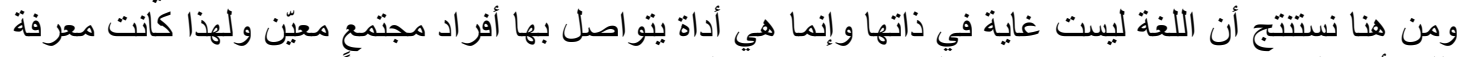

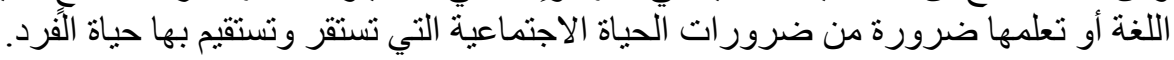
ومن الطريف ما ذكره(Hussain,1983):

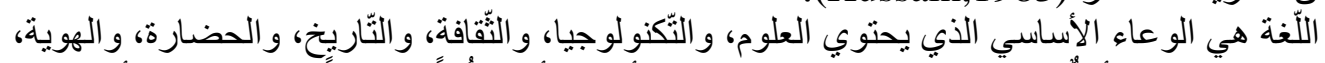

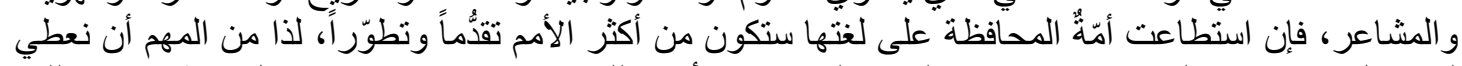

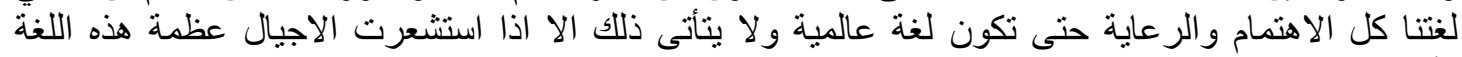

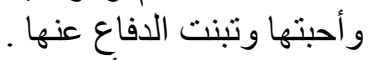

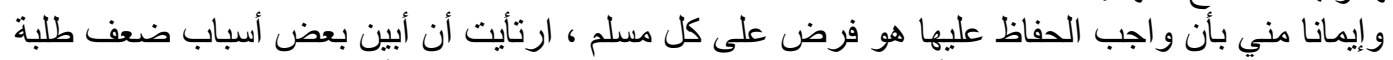

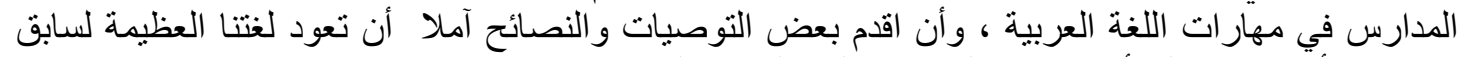

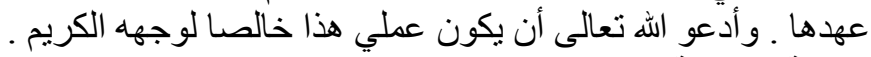

مشكلة الدراسة مادة

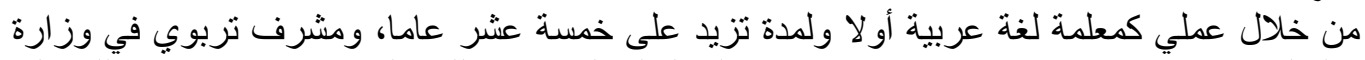

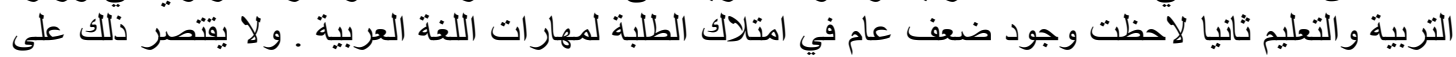

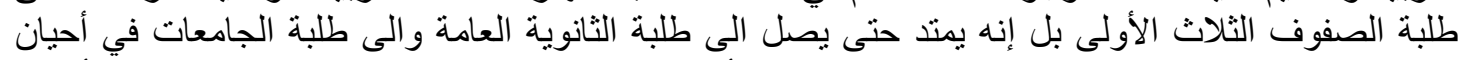

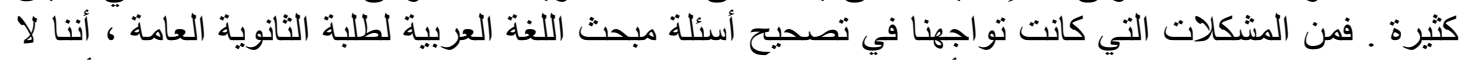

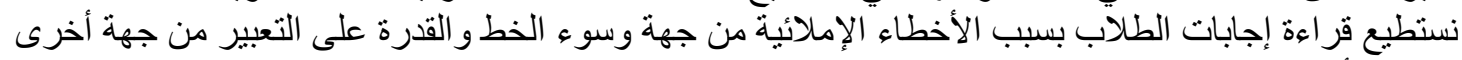

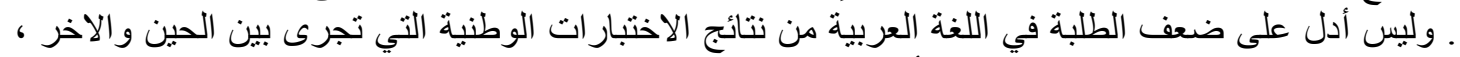

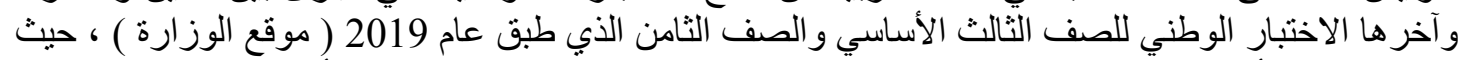

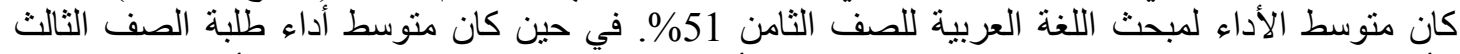

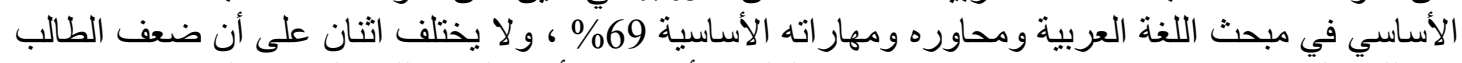

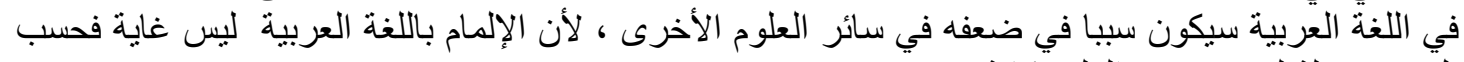
بل هو وسيلة لفهم وتفسير العلوم كافة.

أسئلة الدراسة 


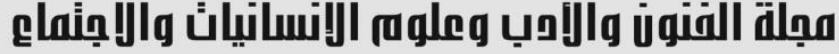

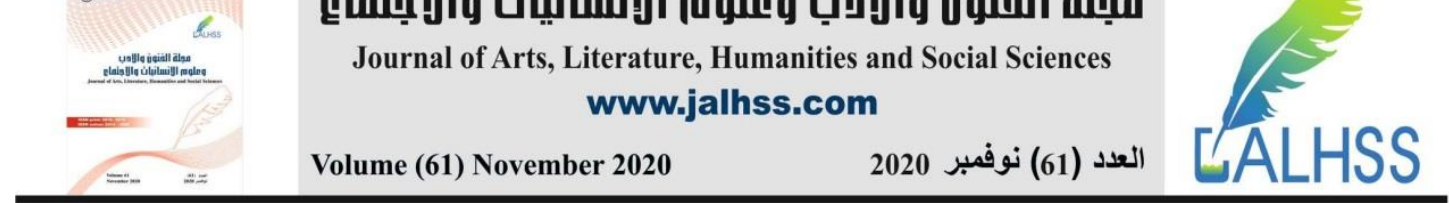

$$
\begin{aligned}
& \text { 1- ما أسباب ضعف طلبة المدارس في مهار ات اللغة العربية ؟ }
\end{aligned}
$$

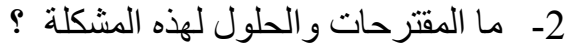

$$
\begin{aligned}
& \text { 3- ما النتائج التي توصلت التهات اليها الباحثة و التوصيات التي توصي بها ؟ }
\end{aligned}
$$

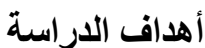

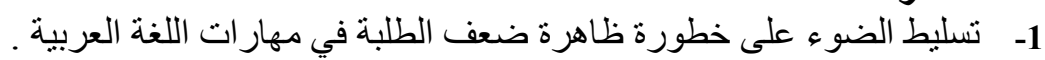

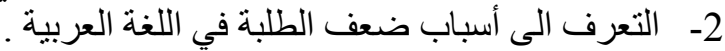

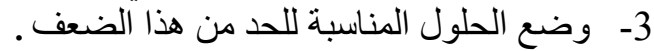

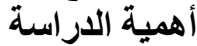

تأتي أهمية البحث من أهمية الموضو ع الذية الذي يتناوله :

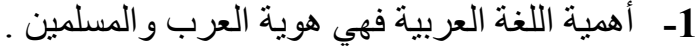

2- استناد البحث على نتائج الاختبار الوطني لعام 2019 و هذا يعني ان ظاهرة الضعف على مستوى طلبة

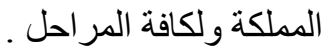
3- إيجاد الحلول لضعف الطلبة في اللغة العربية يعني الحد من ضعف الطلإلبة في العلوم الإنسانية الأخرى .

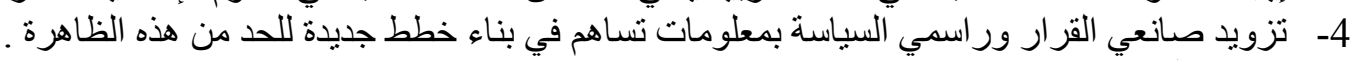
حدود الارباسة اشملت الدراسة على الحدود الآتية: - العد الموضوعي : اقتصرت الدر اسةة في حدها الموضوعي على معرقة أسباب ضعف الطلبة في مهارات

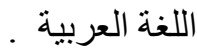

ـ - الحد المكاني: حيث اقتصرت الدر اسة الميدانية على مديرية التربية و التعليم في لواءي الطيبة و الوسطية.

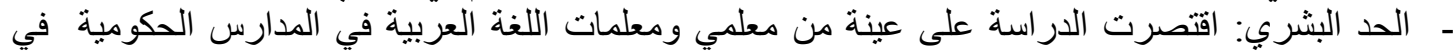
مديرية التربية والتعليم في لواءي الطئية الطيبة و الوسطية.

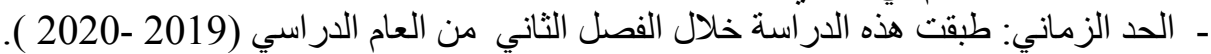
مصطلحات الاراسة : مانة

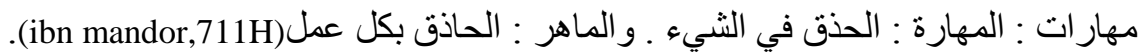

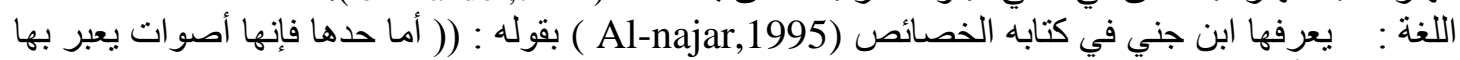

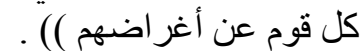
المهار ات اللغويّة (Omar,2008): القدر اتهرات اللاّزمة لاستخدام لغة ما، وهي: الفهم و التحدّث و القر اعة و الكتابة، ـ

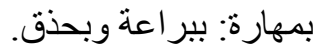
الاختبار الوطني : اختبار سنوي تعده وزارة التربية والتعليم ممنلة بمديرية الاختبار ات في إدارة الامتحانات

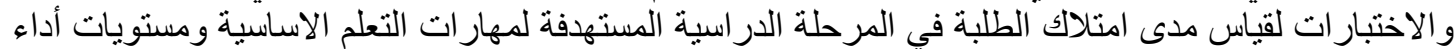

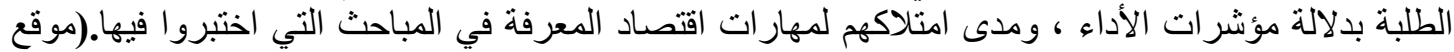

الإطار النظري والار استات السابقة

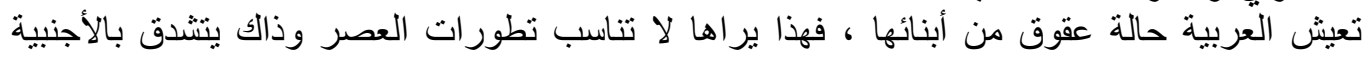

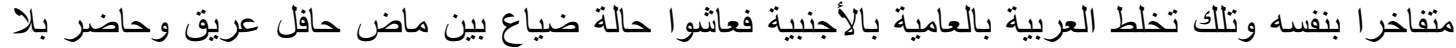

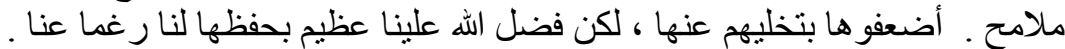

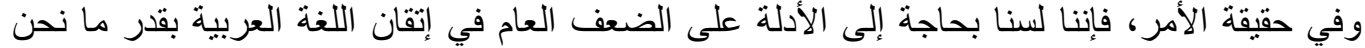

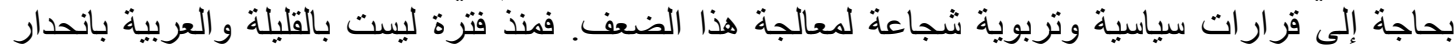

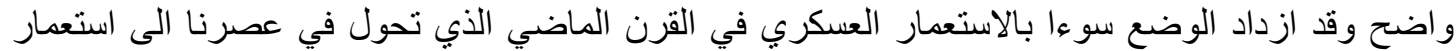

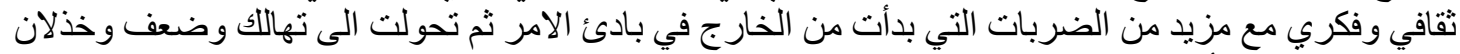

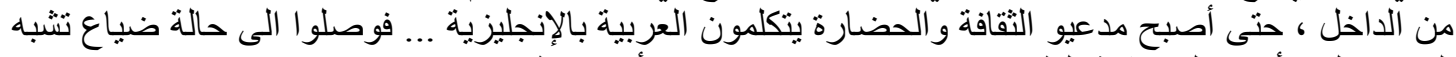

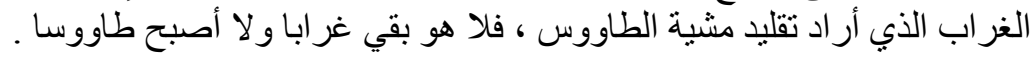




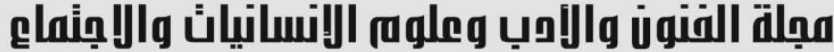

Journal of Arts, Literature, Humanities and Social Sciences www.jalhss.com

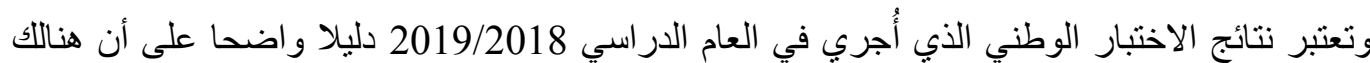

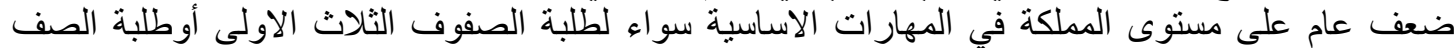

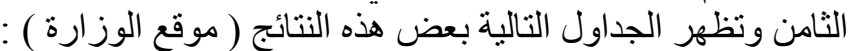

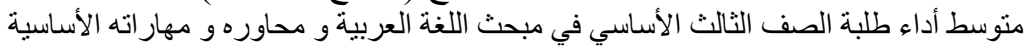

\begin{tabular}{|c|c|c|c|c|c|c|}
\hline & \multicolumn{3}{|c|}{ المهار ات الأساسية لمبحث اللغة العربية } & \multicolumn{3}{|c|}{ محاور مبحث اللغة العربية } \\
\hline متوسط البحث & كتابة كتابية $\quad$ الامية $\quad$ القضايا & وحاكاة الأساليب & 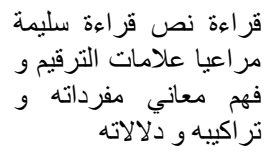 & الكتابة & اللغوية التدريات و الأنماط & القر اءة \\
\hline 68 & 63 & 68 & 76 & 63 & 68 & 76 \\
\hline
\end{tabular}

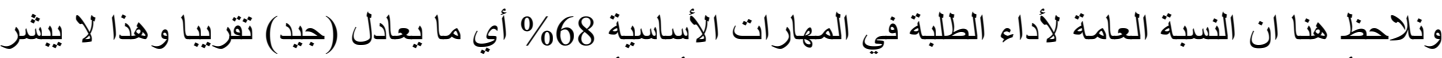

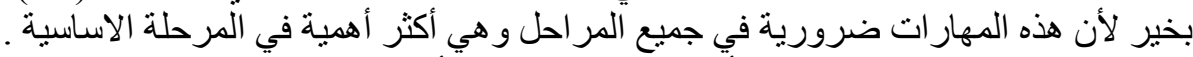

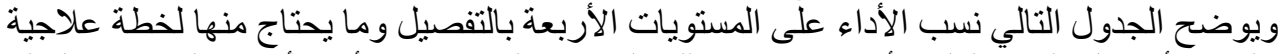

النسب المئوية لأداء طلبة الصف الثالث الأساسي في مبحث اللغة العربية ( على مستويات الأداء الأربع ) على مستوى المملكة

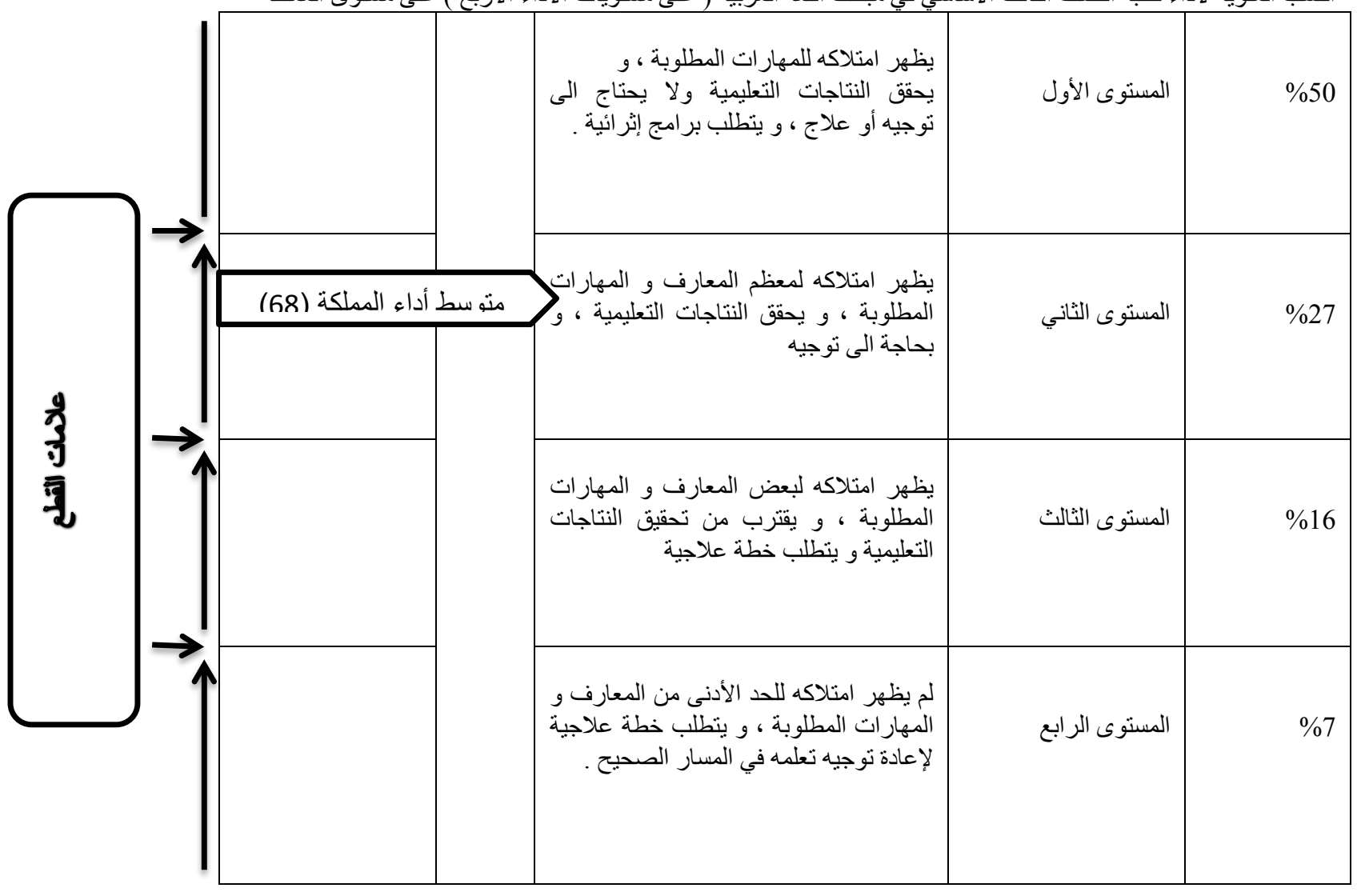




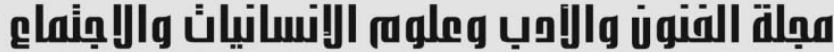

Journal of Arts, Literature, Humanities and Social Sciences www.jalhss.com

ويلاحظ من نتائج الاختبار أن التعليم الخاص يتقدم على غيره بالأفضلية في نتائجه ويليه وكالة الغوث ثم مدارس

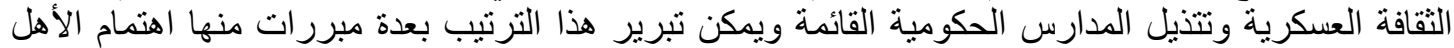

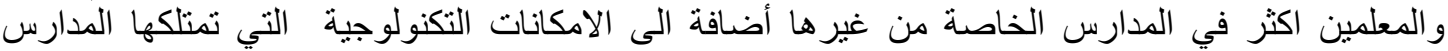

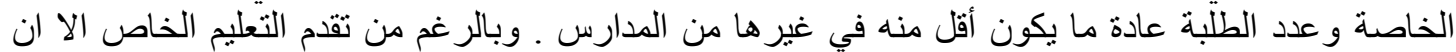

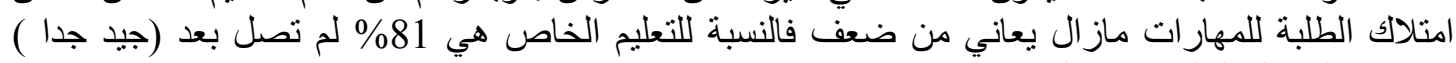

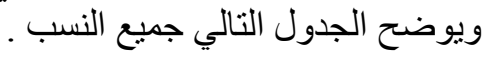

\section{مقارنة بين متوسطات أداء طلبة الصف الثالث الأساسي في مبحث اللغة العربية حسب الجهة المشرفة}

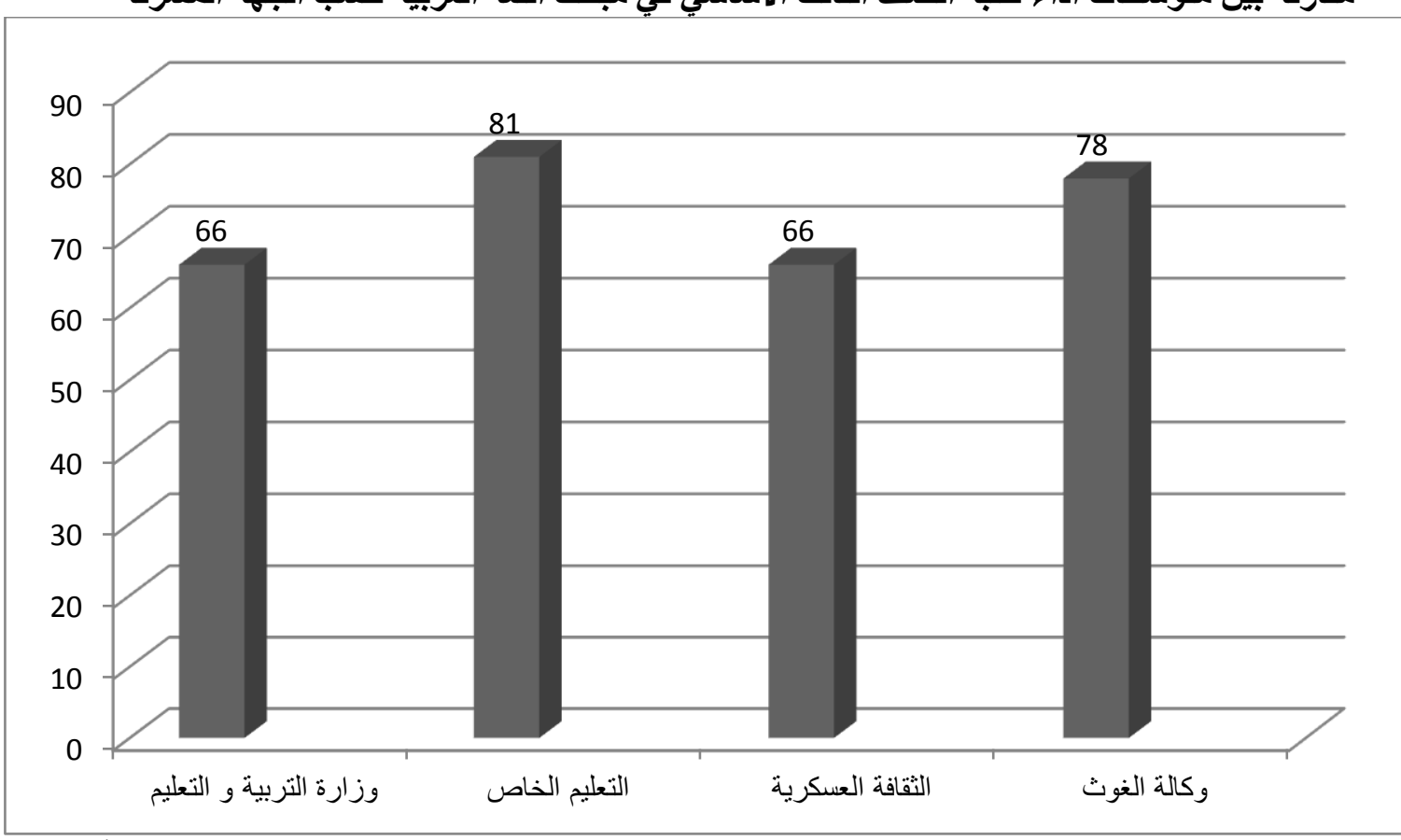

اما بالنسبة لنتائج الصف الثامن فكانت النسبة العامة للمملكة هي 51\% ويوضح الجدول التالي متوسطات أداء

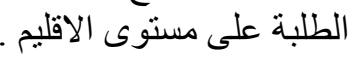
متوسطات أداء طلبة الصف الثامن في مبحث اللغة العربية على مستوى الاقليم

\begin{tabular}{|c|c|}
\hline متوسط الأداء & الاقليم \\
\hline 51 & الوسط \\
\hline 51 & الثمال \\
\hline 48 & الجنوب \\
\hline 51 & مستوى المملكة \\
\hline
\end{tabular}




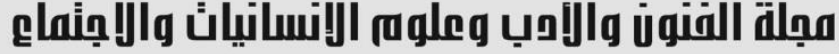

Journal of Arts, Literature, Humanities and Social Sciences www.jalhss.com

Volume (61) November 2020

العدد (61) نوفمبر 2020 - 20 - 20

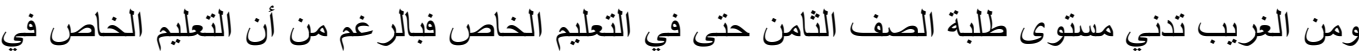

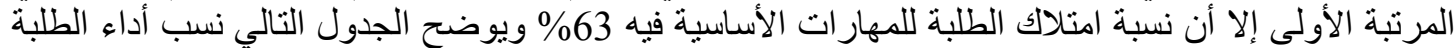

حسب الجهة المشرفة الأنة

متوسطات أداء طلبة الصف الثامن في مبحث اللفة العربية على مستوى السلطة المشرفة

\begin{tabular}{|c|c|}
\hline | منوسط الأداء & السلطة \\
\hline 50 & وزارة التربية و التعليم \\
\hline 63 & التعليم الخاص \\
\hline 46 & الثقافة العسكرية \\
\hline 57 & وكالة الغوث \\
\hline
\end{tabular}

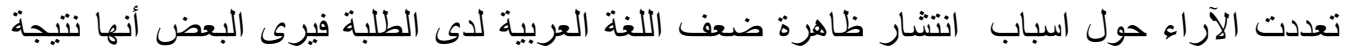

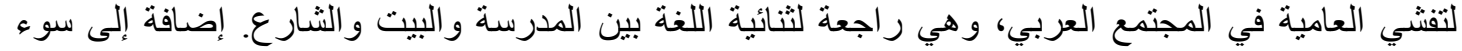

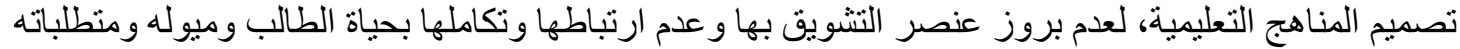

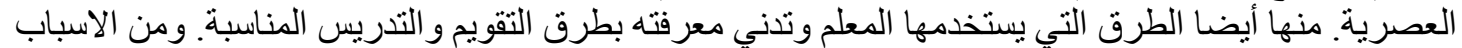

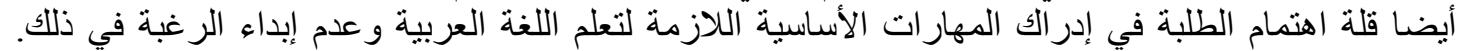

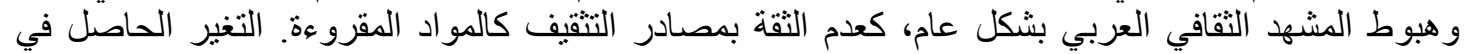

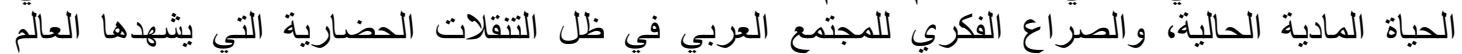

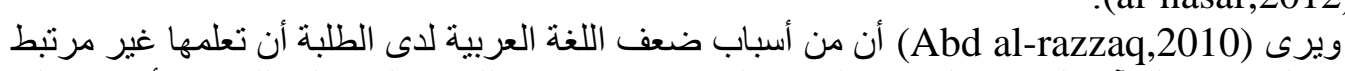
العربي (al-nasar,2012).

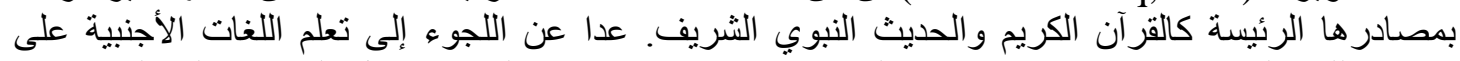

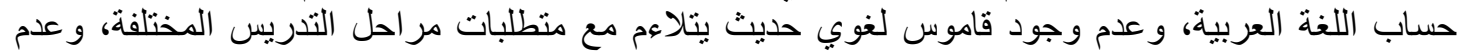

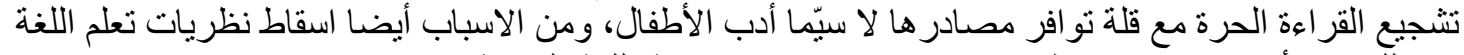

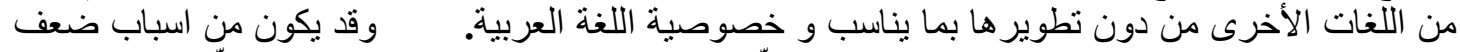

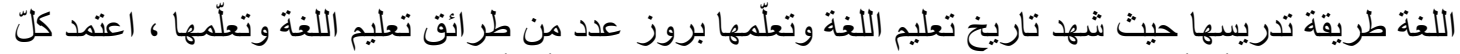

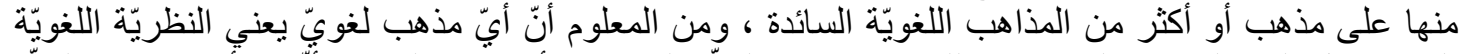

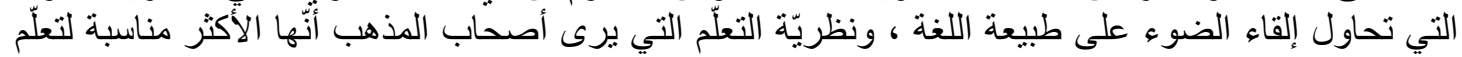

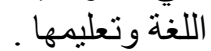

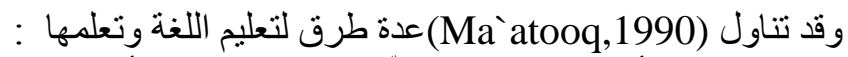

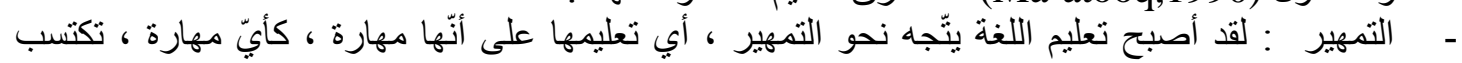

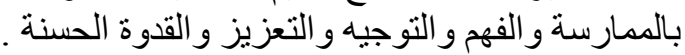

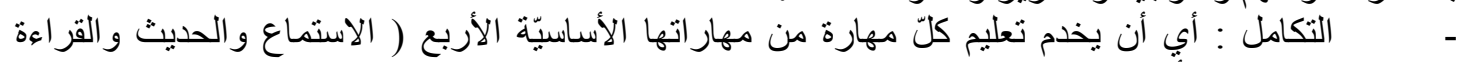




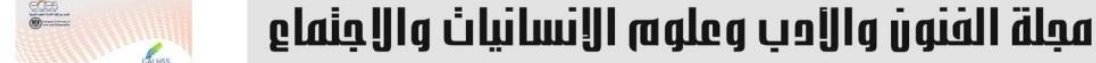

Journal of Arts, Literature, Humanities and Social Sciences www.jalhss.com

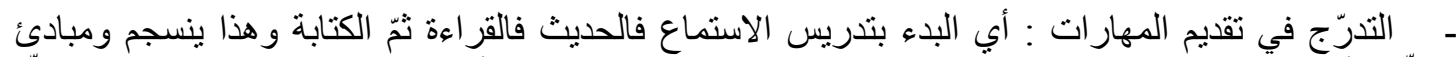

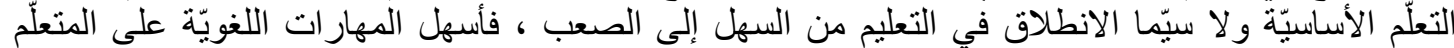

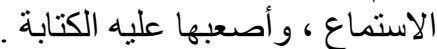
ـ ـ تحديد أهداف التعلّم : فتحديد الأهداف بيساعد على اختيار الطريق الأنسب لبلو غها ، و الوسائل المساعدة على

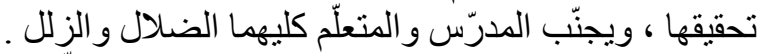

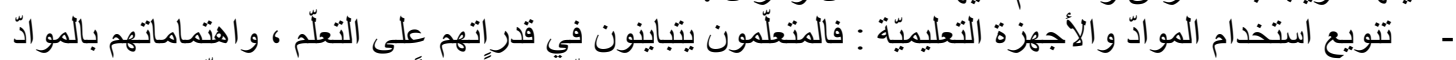

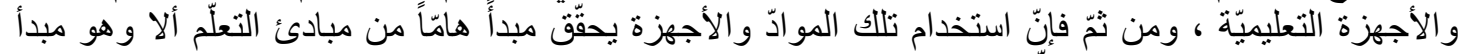

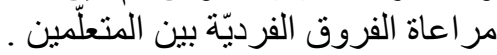

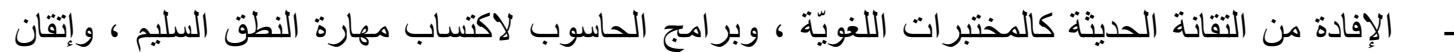

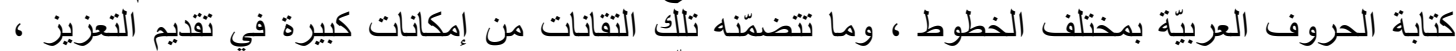

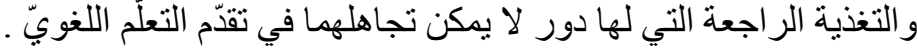

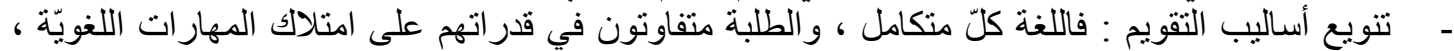

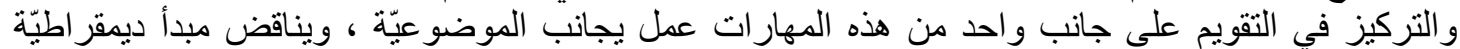

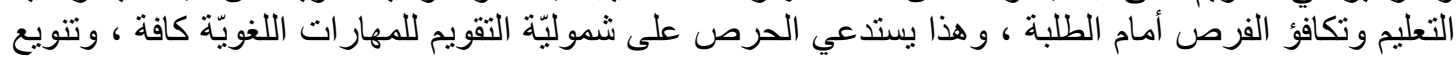

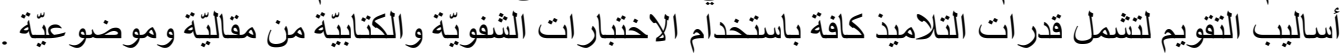

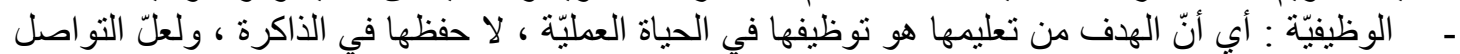

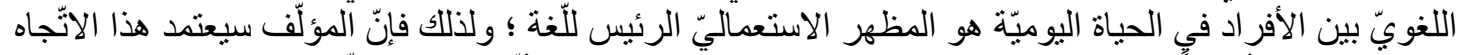

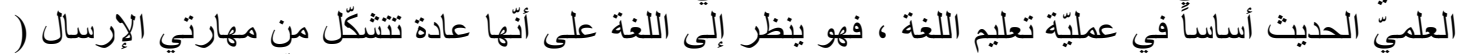

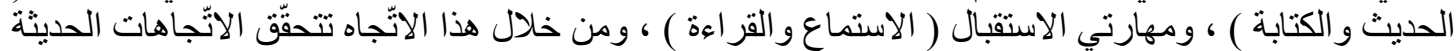

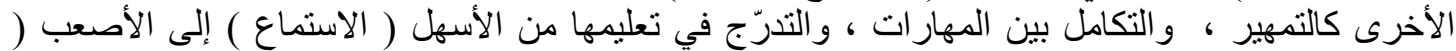

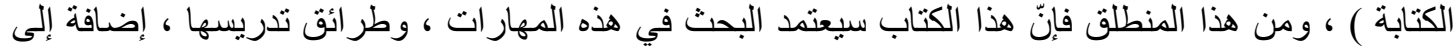

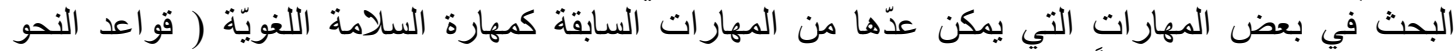

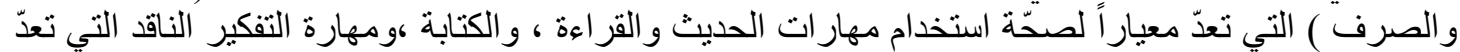

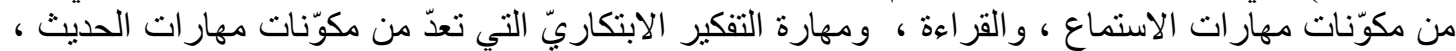

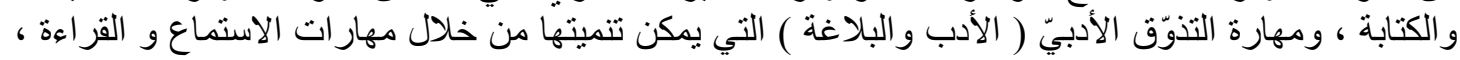
و الكتابة

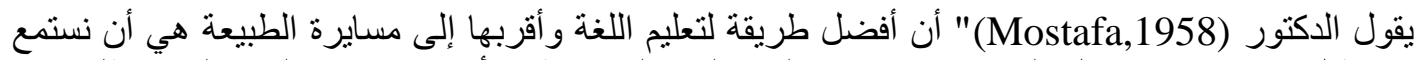

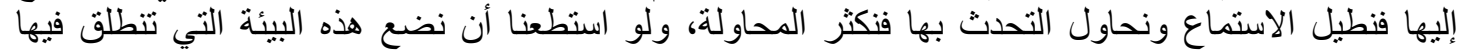

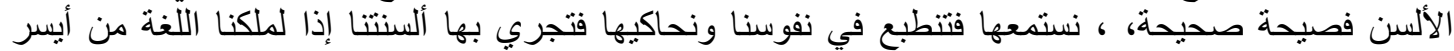

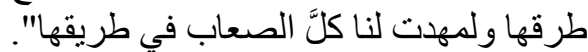

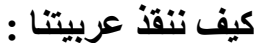

كما أن أسباب ضعف الطلبة في اللغة العربية كثيرة ومتعددة فوسائل الحفاظ عليها أيضا متنوعة لأنها مرتبطة

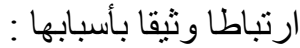

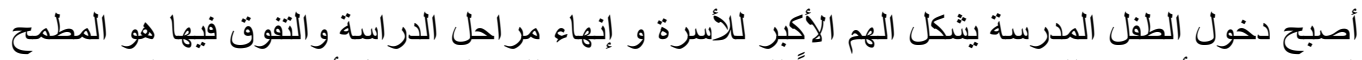
المدرسة

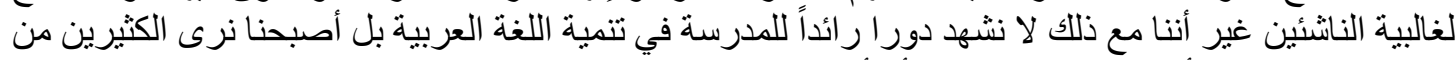

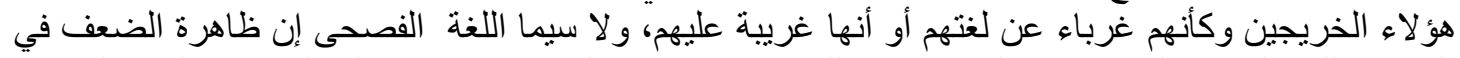

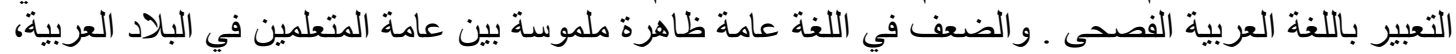

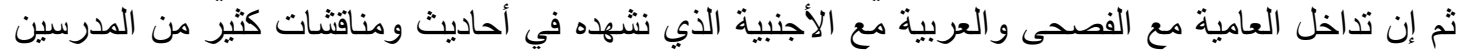
وطائفة كبيرة من المثنقين(ma`atoq,1990).

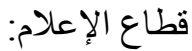

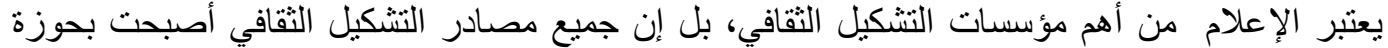

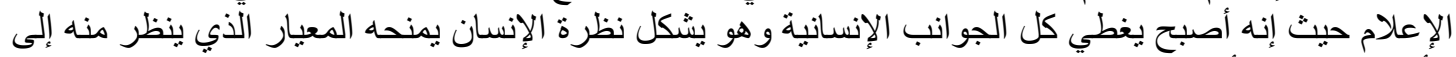

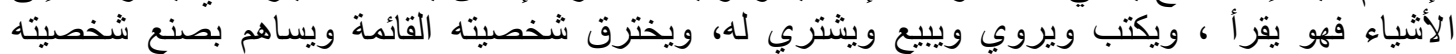




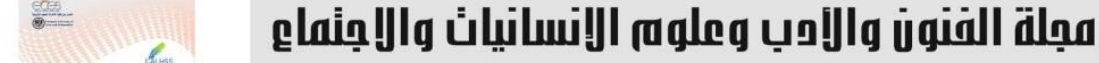

Journal of Arts, Literature, Humanities and Social Sciences www.jalhss.com

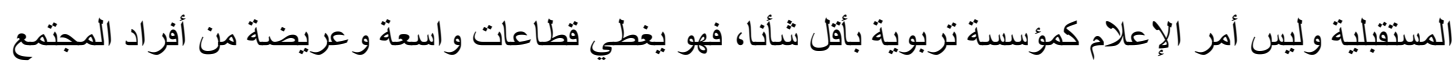

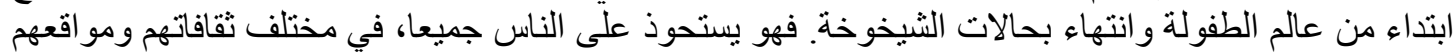

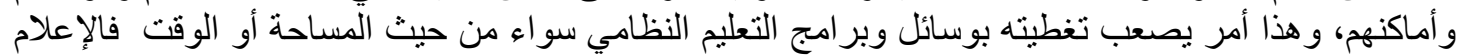
تعلم دائم ومستمر ولكل الأجيال (blabel,2001) .

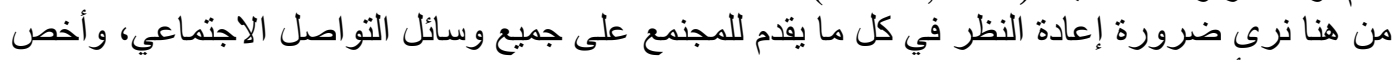
بالذكر ما يقدم للأطفال على شانشة التلفاز .

للمعلم في المدرسة أثر كبير ومبانر على تلامذته سواء من الناحية السلوكية أو من الناحية العلمية

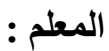

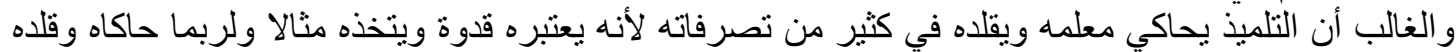

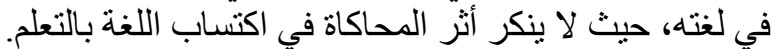

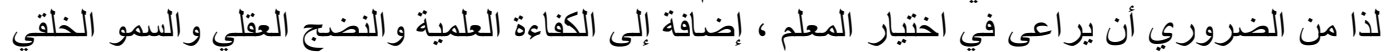

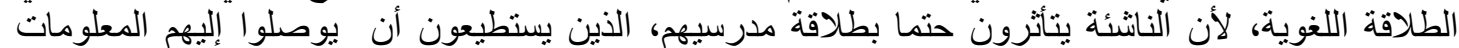

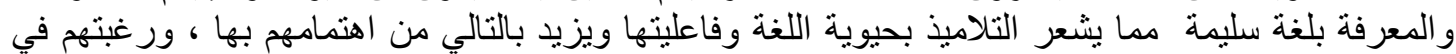
تحصيل المزيد من مفرداتها وقو اعدها (ma`atooq,1990).

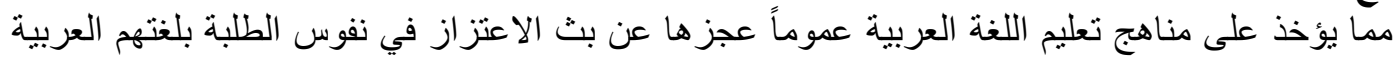

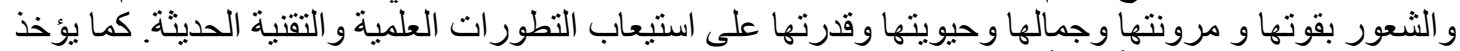

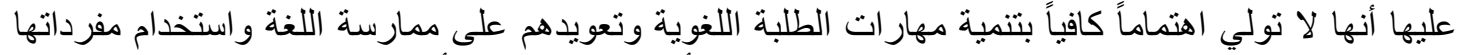

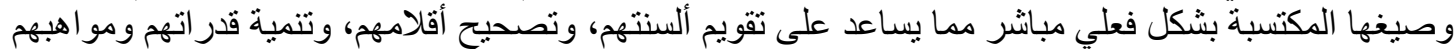
الكتابية و الخطابية، و إثارة الحماسة فيهم لتعلم اللغة و البر اعة فيها (ma`atooq,1990) .

ثُانياً: الاراسات السابقة دراسة (Al-mosawe,2009) حيث هدفت التعرف الى الاسباب التي أدت إلى تدني مستوى القراءة و الكتابة

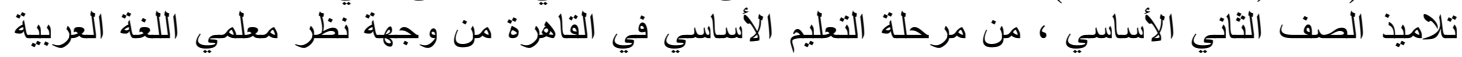

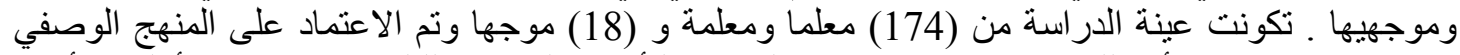

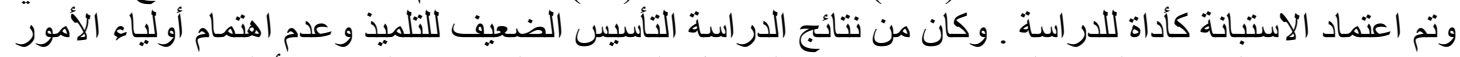

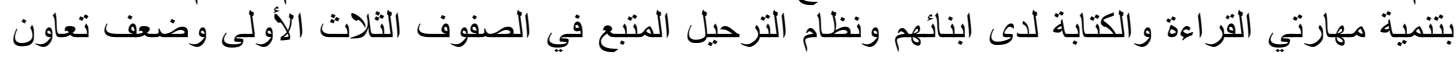

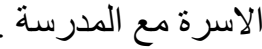

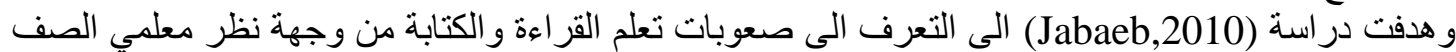

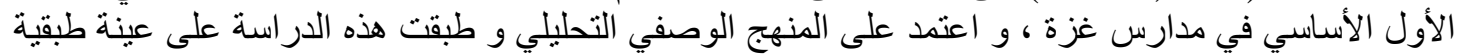

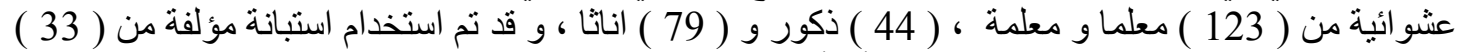

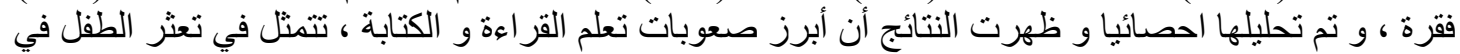

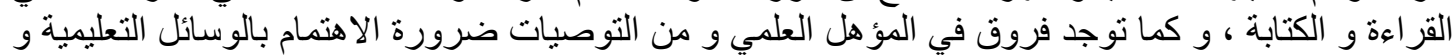

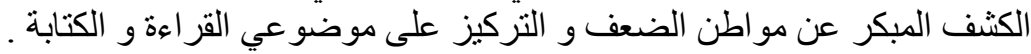

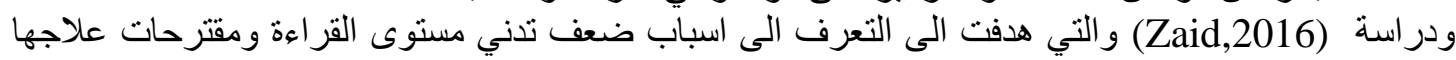

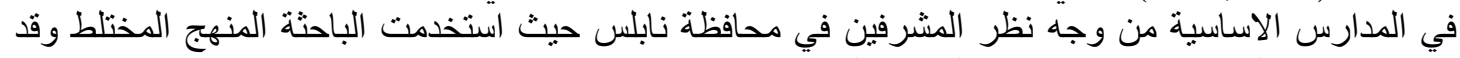

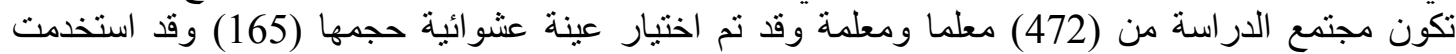

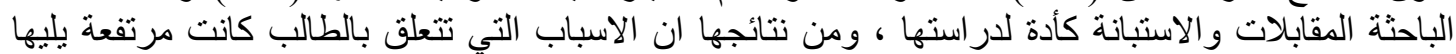

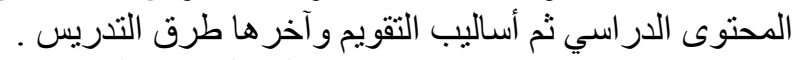

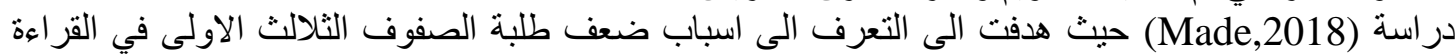

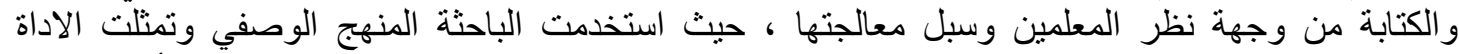

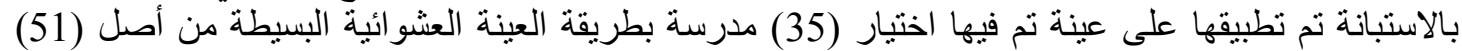
مدرسة واختبار (100) معلم ومعلمة من هذه المدارس من أصل مدل (300) وبنسبة 30\% مثنة وتم استطلاع رأي 


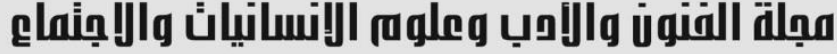

Journal of Arts, Literature, Humanities and Social Sciences www.jalhss.com

Volume (61) November 2020

العدد (61) نوفمبر 2020

ل(25) معلما ومعلمة من معلمي المرحلة الاساسية من الصف الاول الى الثالث ومن نتائجها ان اسباب ضعف فئس

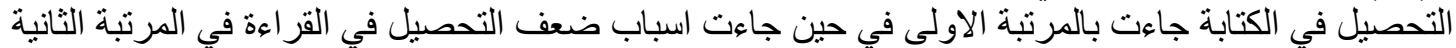

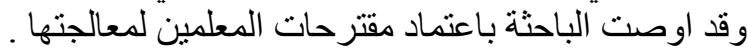

التعقيب على الاراسات السابقة:

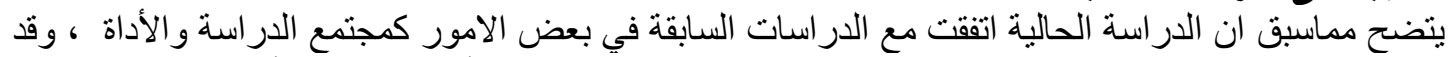

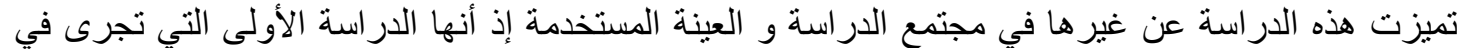

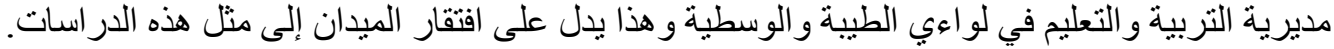

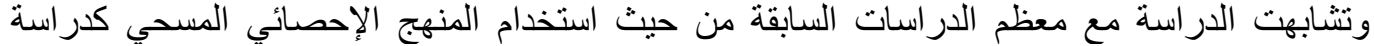
(Zaid,2016) ودر اسة (Jabaeb,2010)، واستخدام الاستبانة كأداة لجمع البيانات من مجتمع الدراسة كدراسة (Al-mosawe,2009) لذا يمكن القول بأن الدراسات السابقة قد اختلفت مع الدراسة الحالية في أكثر من جانب، وتثابهت معها في جو انب عدة، و هذا يعني أنَّ الباحثة قد استفادت من الدر اسات في إعداد هذه الدر اسة.

$$
\begin{aligned}
& \text { الطريقة والإجراءات }
\end{aligned}
$$

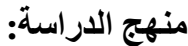

$$
\begin{aligned}
& \text { لتحقيق أهداف الدراسة وللإجابة عن أسئلتها تم استخدام المنهج الوصفي المسحي. }
\end{aligned}
$$

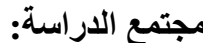

بتكون مجتمع الدراسة من جميع معلمي ومعلمات اللغة العربية في المدارس الحكومية في مديرية التربية والتعليم في لواءي الطيبة و الوسطية .

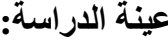

تم اختيار عينة الدر اسة بالطريقة القصدية ممثلة لمجتمع الدراسة، خلال العام الدراسي (2019-2020) بما نسبته ( 90 (100)

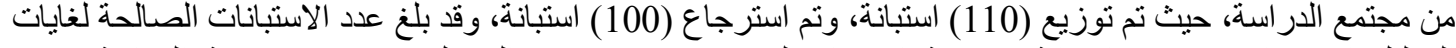

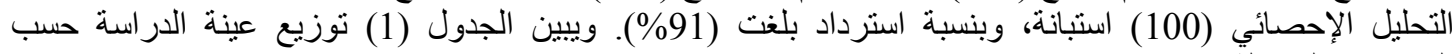

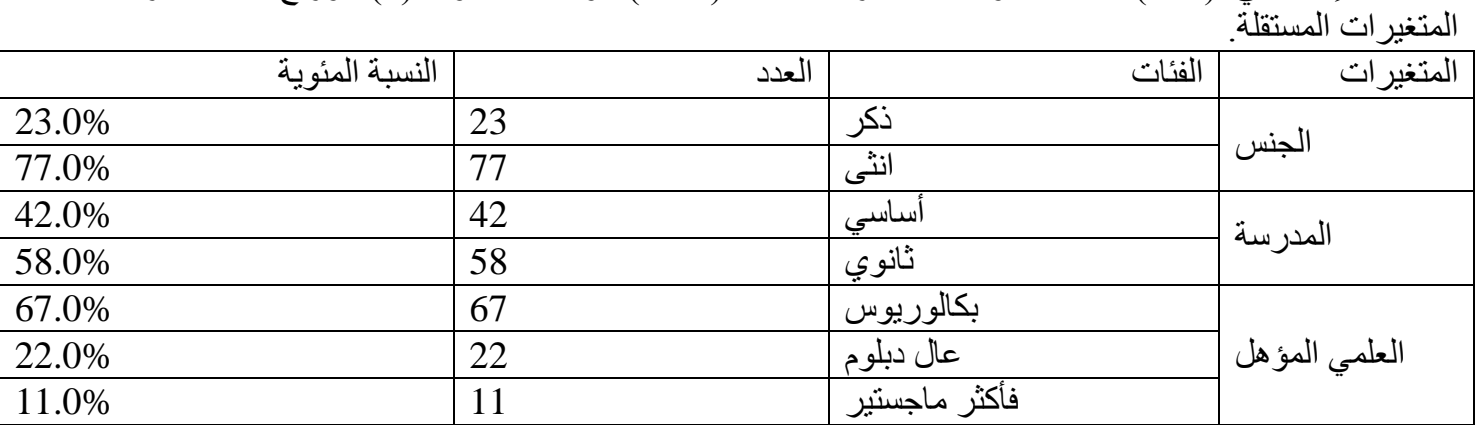

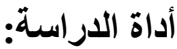

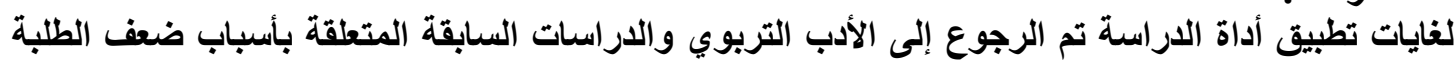

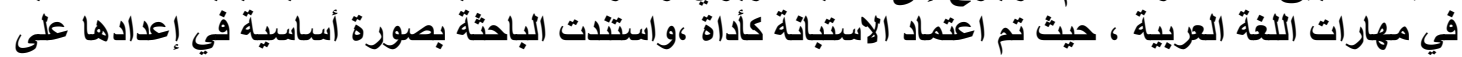
الذقاييس المستخدمة في الاراسات السابقة.

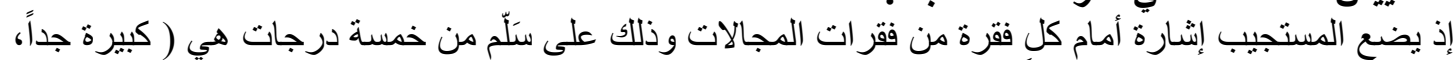

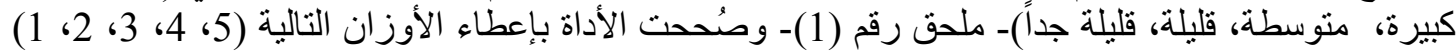
للارجات السابقة الذكر ، كما تم التحقق من دلالات الصدق التات و الثبات للأداة.

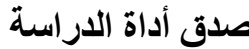

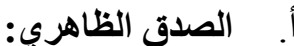

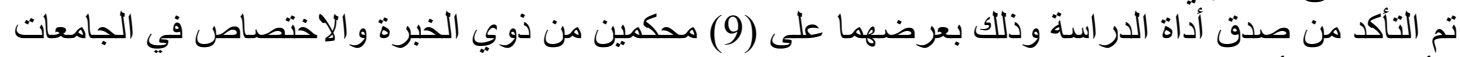

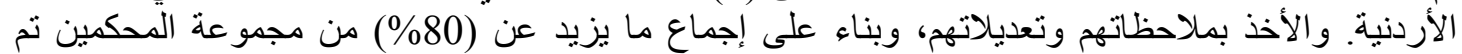

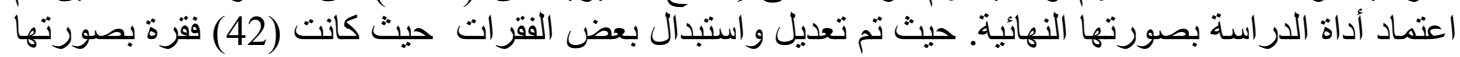




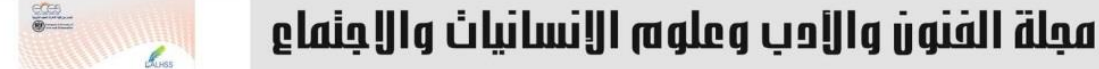

Journal of Arts, Literature, Humanities and Social Sciences www.jalhss.com

الأولية لبصبح عددها النهائي (39) فقرة تتعلق بأسباب ضعف الطبة في اللغة العربية، وطرق علاج الضعف

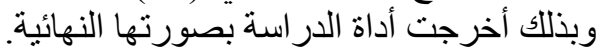

أولاً: صدق البناء (المحتوى) لأداة الاراسة

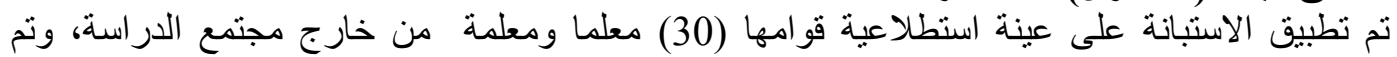

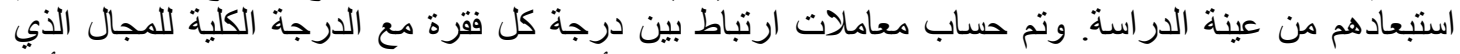

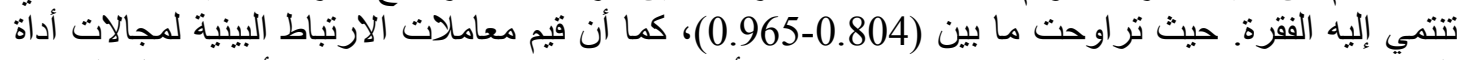

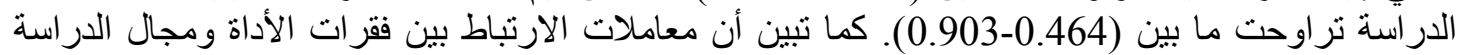

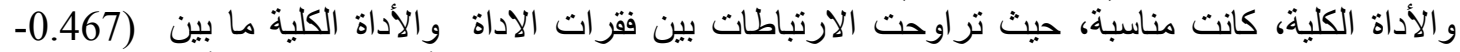

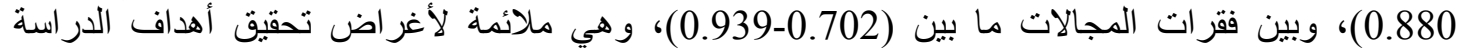

ثُانياً: ثبات أداة الدراسة : مانة تمّ استخدام طريقتين للتحقق من ثبات أداة الدراسة، الطريقة الأولى هي الأبـات الاختبار و إعادة الاختبار و الطريقة الثانية

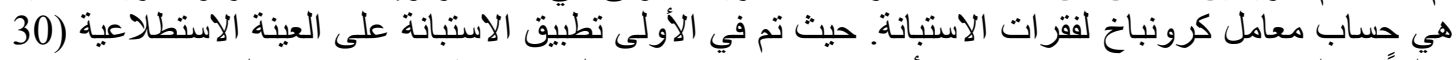

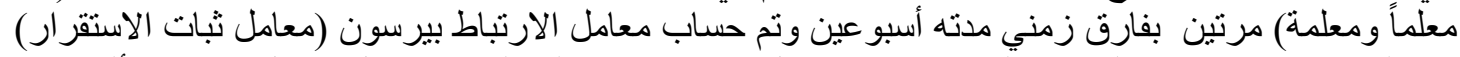

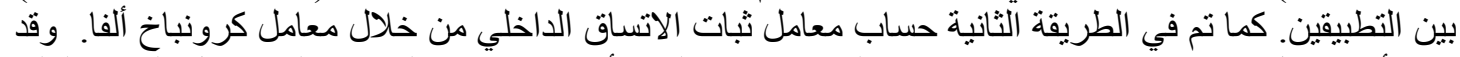

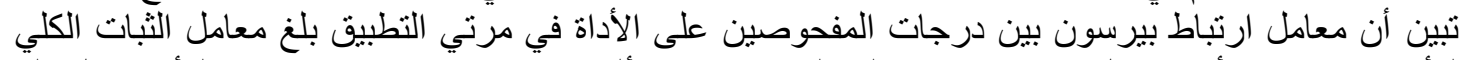

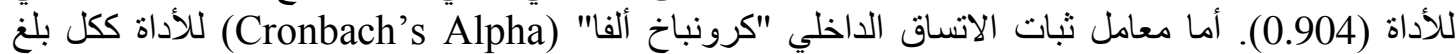

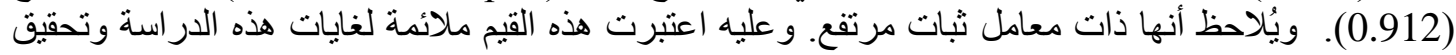

غرضهاو الوثوق بنتائجها.

تصحيح أداة الاراسة

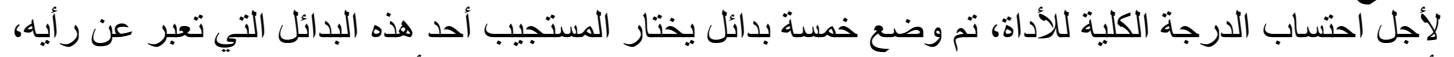

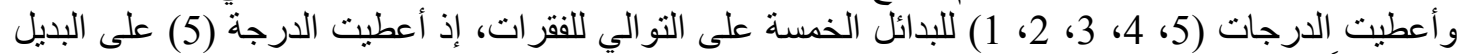

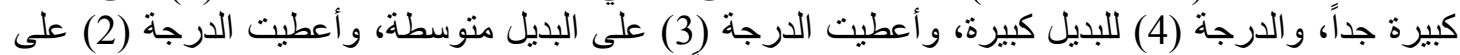

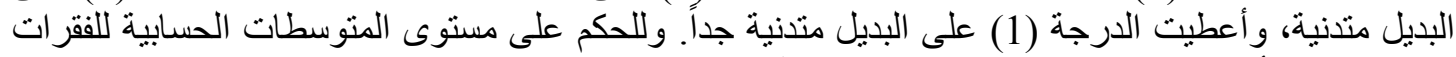

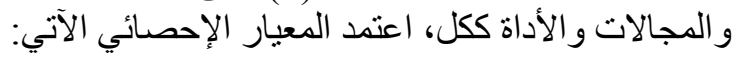
الجدول (2): المعيار الإحصائي لتحديد درجة الاداة

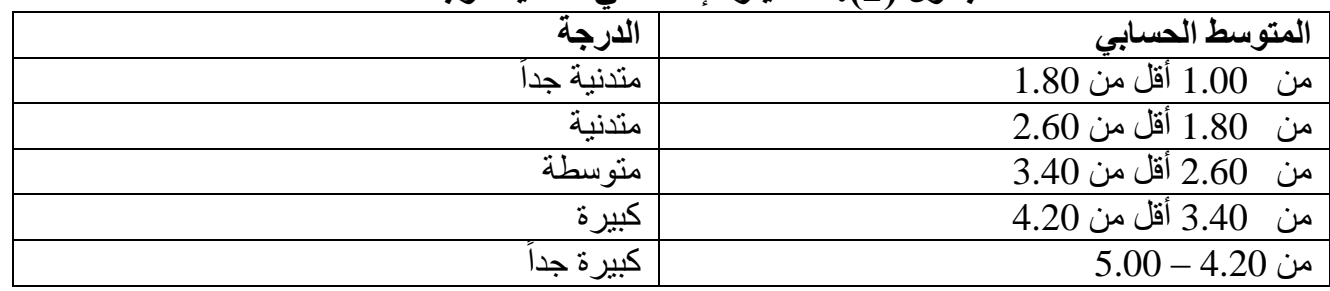

أساليب المعالجة الإحصائية:

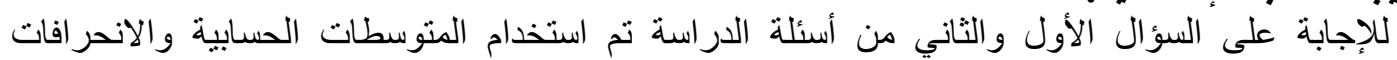

نتائج السؤال الأول الذي نص على: " ما أسباب ضعف الطلبة في مهارات اللغة العربية من وجهة نظر

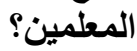
للإجابة عن هذا السؤال؛ نم حساب المتوسطات الحسابية والانحر افات المعيارية لتقديرات أفراد عينة الدراسة

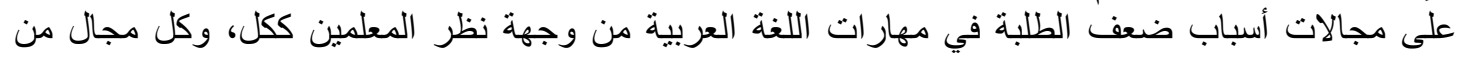
مجالاتها، ويبين جدول (3) ذلاب فلك. 


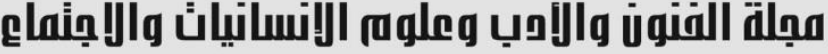

Journal of Arts, Literature, Humanities and Social Sciences www.jalhss.com

Volume (61) November 2020
العدد (61) نوفمبر 2020

جدول (3): المتوسطات الحسابية والانحرافات المعيارية لتقديرات أفراد عينة الدراسة على فقرات أسباب

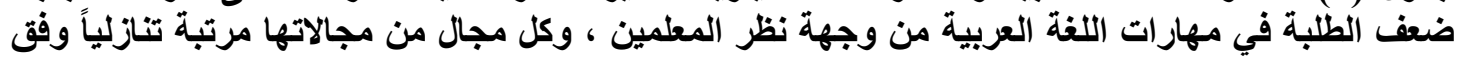

\begin{tabular}{|c|c|c|c|c|c|}
\hline الارجة & الرتبة & الالحعراف & المستوسبط & 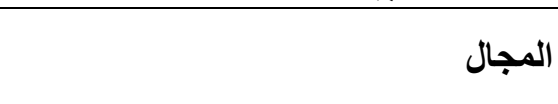 & رقمجال \\
\hline كبيرة & 1 & .60 & 3.9 & اسباب تتعلق بالطلبة & 3 \\
\hline كبيرة & 2 & .74 & 3.6 & أسباب تتعلق بالكتاب الددرسي & 2 \\
\hline كبيرة & 3 & .68 & 3.2 & أسباب تتعلق بالمعلم & 1 \\
\hline كبيرة & & .55 & 3.6 & أسباب ضعف الطلبة في مهار ات اللغة العربية & \\
\hline
\end{tabular}

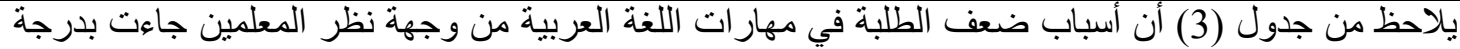

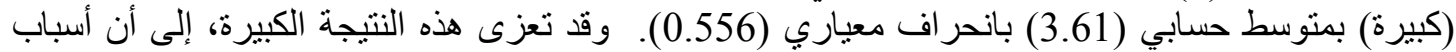

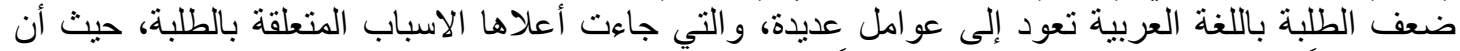

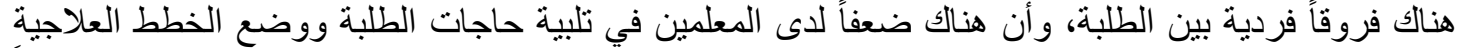

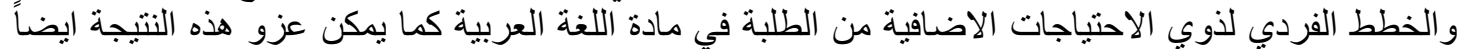

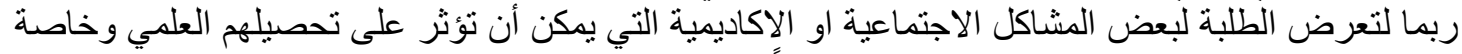

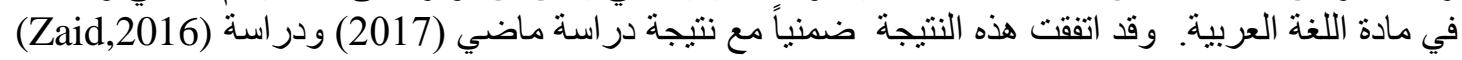
، ودراسة (Jabaeb,2010) ، ودر اسة (al-mosawe,2009).

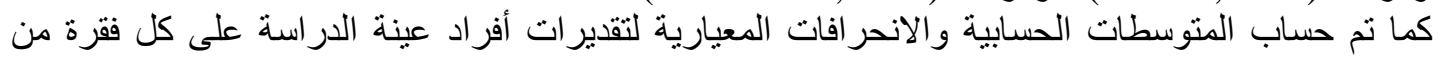

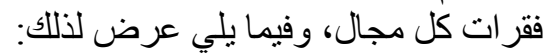
المجال الأول: أسباب تتعلق بالمعلم :

الجدول (4): المتوسطات الحسابية والانحرافات المعيارية لتقديرات أفراد عينة الداراسة على فقرات المجال

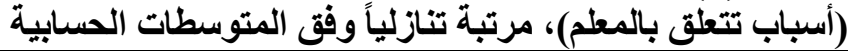

\begin{tabular}{|c|c|c|c|c|c|}
\hline 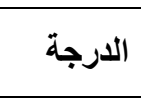 & 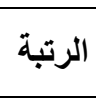 & المعياري & المستوسط & الفقزة & رقاق \\
\hline كبيرة جداً & 1 & .91 & 4.3 & ضصص الوقت وانشغاله بالأعمال لإعداد الأخرى الوسائل التعليمية لارتفاع نصابه من & 8 \\
\hline كبيرة & 2 & .92 & 4.1 & فلة الحو افز المادية و المعنوية للمعلم المبدع و المتميز. . ع & 6 \\
\hline كبيرة & 3 & .99 & 3.6 & قلة اقتناع المعلمين باستر اتيجيات التدريس الحديثة. & 3 \\
\hline كبيرة & 4 & .89 & 3.4 & قلة التنويع في الانشطة التعليمية. & 4 \\
\hline متوسطة & 5 & 1.0 & 3.3 & استخدام استر اتيجيات تدريس تعتمد على التلقين & 2 \\
\hline متوسطة & 6 & 1.1 & 3.3 & عدم قناعة المعلمين بالتغير و البقاء على نفس الاسلوب في التعليم & 5 \\
\hline متوسطة & 7 & 1.0 & 3.0 & استخدام اللهجة العامية في التدريس. & 10 \\
\hline 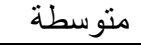 & 8 & 1.0 & 2.9 & افتقار المعلم لمهار ات الاتصـال والتو اصل مع الطلبة. & 7 \\
\hline متوسطة & 9 & 1.3 & 2.9 & إهمال بعض المعلمين لمهارتي الاستماع و المحادثة. & 12 \\
\hline متوسطة & 10 & 1.2 & 2.9 & ضعف إعداد المعلمين اكاديمياً وتربويا. & 1 \\
\hline متوسطة & 11 & 1.1 & 2.7 & إهمال المعلم للتلميذ الضعيف. & 9 \\
\hline متوسطة & 12 & 1.1 & 2.6 & قلة ربط مهار ات اللغة العربية ببعضها في أثناء التندريس. & 11 \\
\hline متوسطة & & .68 & 3.2 & أسباب تتعلق بالمعلم & \\
\hline
\end{tabular}

يلاحظ من جدول (4) أن المتوسطات الحسابية لفقر ات المجال تراوحت بين (2.66) و و(4.31) بدرجة (متوسطة

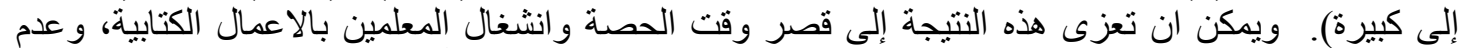

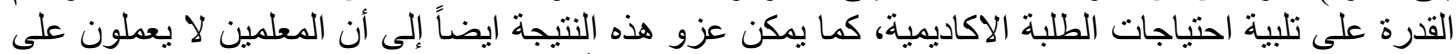

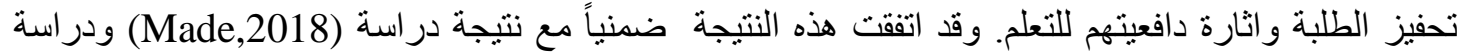

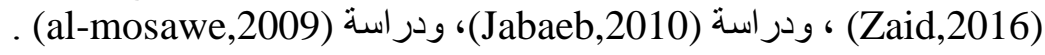




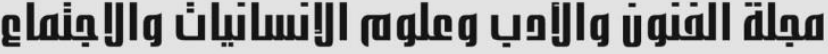

Journal of Arts, Literature, Humanities and Social Sciences www.jalhss.com

Volume (61) November 2020
العدد (61) نوفمبر 2020

المجال الثاني: أسباب تتعلق بالكتاب المدرسي :

الجدول (5): المتوسطات الحسابية والانحرأفات المبات المعيارية لتقايرات التبات أفراد عينة الدراسة على فقرات المجال

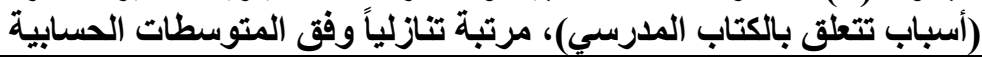

\begin{tabular}{|c|c|c|c|c|c|}
\hline الارجة & 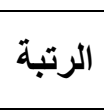 & الانحرياري & المستوسطي & | - الفقرة & رققرة \\
\hline كبيرة جداً & 1 & .88 & 4.2 & عدم اشر اك المعلمين في وضع الكتب المدرسية. & 1 \\
\hline 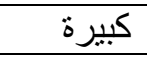 & 2 & .93 & 3.8 & ضعف ارتباط المحتوى بالمنظومة الاجتماعية. & 2 \\
\hline 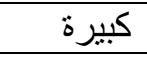 & 3 & 1.2 & 3.8 & عدم وجود أدلة تساعد في توضيح الكتاب المدرسي. & 7 \\
\hline 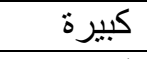 & 4 & 1.1 & 3.5 & عدم مر اعاة المحتوى للقضايا و الموضو عات المعاصرة. & 6 \\
\hline كبيرة & 5 & 1.0 & 3.4 & إهمال الجانب المهاري التطبيقي في الكتاب. & 4 \\
\hline متوسطة & 6 & .97 & 3.3 & ضعف ارتباط المحتوى بالمباحث الدراسية الاخرى. & 3 \\
\hline 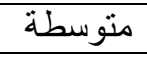 & 7 & 1.2 & 3.0 & لا يتناسب محتوى الكتاب مع المدة الزمنية المحددة لتنفيذه & 5 \\
\hline كبيرة & & .74 & 3.6 & أسباب تتعلق بالكتاب المدرسي & \\
\hline
\end{tabular}

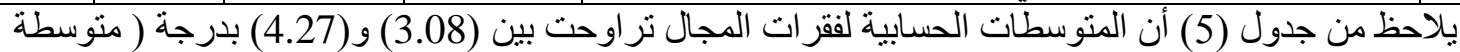

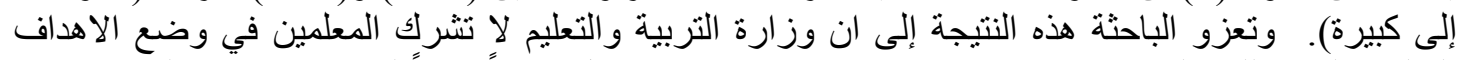

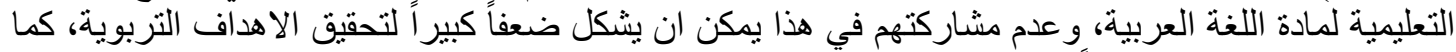

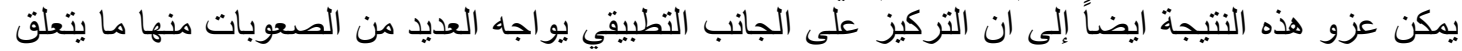

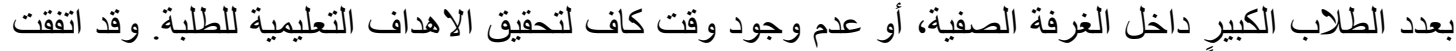
هذه النتيجة ضمنياً مع نتيجة در اسة (Made,2018) ودر اسة (Zaid,2016)، ودر اسة (Jabaeb,2010)،

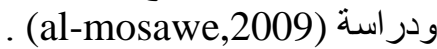

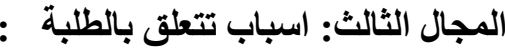

الجدول (6): المتوسطات الحسابية والانحرافات المعيارية لتقديرات أفراد عينة الدراسة على فقرات المجال

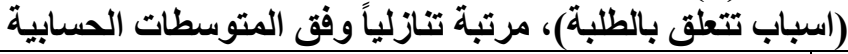

\begin{tabular}{|c|c|c|c|c|c|}
\hline الدرجة & 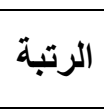 & الانحراف & الحستوسيط & 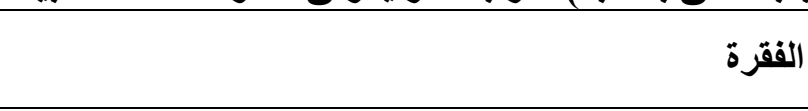 & رققرة \\
\hline كبيرة جداً & 1 & .93 & 4.4 & انشغال الطلبة بالتكنولوجيا الحديثة. & 11 \\
\hline كبيرة جدأ & 2 & .79 & 4.4 & عدم اهتمام الطلبة بمطالعة الكتب الخارجية. & 7 \\
\hline كبيرة جداً & 3 & .92 & 4.3 & قلة حفظ الطلبة من القرآن الكريم و الحديث الشريف. & 1 \\
\hline كبيرة جداً & 4 & .81 & 4.2 & امتداد ضعف الطلبة من المرحلة الاساسية الى المر احل التالية & 5 \\
\hline كبيرة جدأ & 5 & 1.0 & 4.2 & اتجاهات الطلبة السلبية نحو اللغة العربية. & 2 \\
\hline 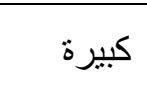 & 6 & .96 & 3.9 & قلة اهتمام الاهل بالنواحي الصحية و النفسية و التربوية لأبنائهج & 3 \\
\hline كبيرة & 7 & 1.1 & 3.9 & الانتقال المفاجئ في تعليم اللغة للطفل من العامية للفصحى. & 8 \\
\hline كبيرة & 8 & .96 & 3.7 & ضعف الاتصال بين أولياء الامور و المعلمين & 4 \\
\hline 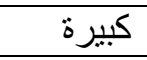 & 9 & 1.2 & 3.7 & عدم وجود بر امج علاجية للطلبة ذوي التحصيل المتندي. & 10 \\
\hline كبيرة & 10 & 1.2 & 3.7 & تالاوليم اللغة العربية بالمزامنة مع الانجليزية منذ الصفوف & 6 \\
\hline متوسطة & 11 & 1.1 & 2.6 & خوف الطلبة من المعلم. & 9 \\
\hline 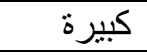 & & .60 & 3.9 & اسباب تتعلق بالطلبة & \\
\hline
\end{tabular}




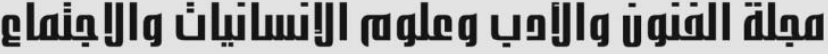

Journal of Arts, Literature, Humanities and Social Sciences www.jalhss.com

Volume (61) November 2020
العدد (61) نوفمبر 2020

يلاحظ من جدول (6) أن المتوسطات الحسابية لفقرات المجال نراوحت بين (2.69) و (4.47) بدرجة (متوسطة

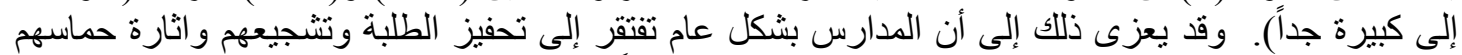

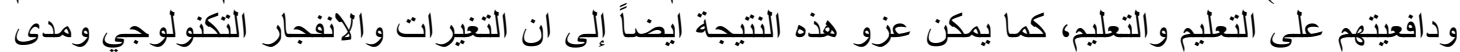

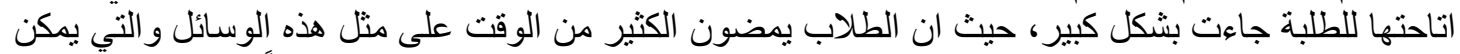

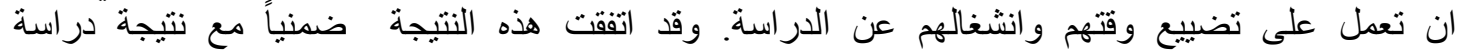

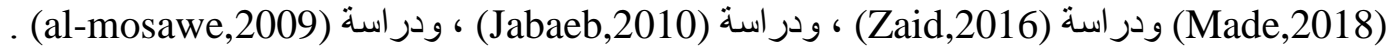

نتائج السؤال الثاني الذي نص على: " ما طرق علاج ضعف الطلبة في مادة اللغة العربية من وجهة نظر

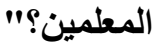

للإجابة عن هذا السؤال؛ تم حساب المتوسطات الحسابية والانحر افات المعيارية لتقديرات أفراد عينة الدراسة الدية على فقرات طرق العلاج ضعف الطلبة في مادة اللغة العربية من وجهة نظر المعلمين ، ويبين جدول (7) ذلك.

الجدول (7): المتوسطات الحسابية والاتحرافات المعيارية لتقديرات أفراد عينة الدراسة على فقرات مجال

\begin{tabular}{|c|c|c|c|c|c|}
\hline & & & & \multicolumn{2}{|l|}{ (طرق العُلاج)، مرتبة تنازلياً وفق المتوسطات الحسابية } \\
\hline الارجة & 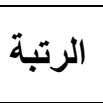 & المعياري & | المستوسطي * & 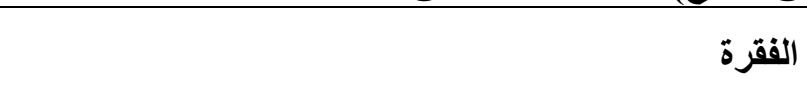 & ر الفقرة \\
\hline كبيرة جداً & 1 & .48. & 4.8 & ضردورة اخضاع الطالب الجامعي للتنريب و التطبيق في & 3 \\
\hline كبيرة جداً & 2 & .60 & 4.7 & في الكتب من نصدسية. القرآن الكريم والحديث النبوي الثريف & 1 \\
\hline كبيرة جداً & 3 & .82 & 4.6 & ايجاد غرف صعوبات تعلم في جميع المدارس. & 6 \\
\hline كبيرة جداً & 4 & .97 & 4.6 & تقليل عدد الطلبة في الصفوف بالذات طلبة المرحلة الاساسية & 4 \\
\hline كبيرة جداً & 5 & .90 & 4.6 & تخفيف انصبة المعلَّين وتقليل الاعباء الورقية عنهم. & 9 \\
\hline كبيرة جداً & 6 & .71 & 4.5 & تثادية والمعنوية. المنميزين في المسابقات من خلال الحوافز & 7 \\
\hline كبيرة جداً & 7 & .88 & 4.5 & اشر الك المعلمين في وضع المناهج الدر اسية. & 2 \\
\hline كبيرة جداً & 8 & 1.0 & 4.4 & اخضاع المعلمين للتأهيل قبل الدخول على الغرفة الصفية. & 5 \\
\hline كبيرة جدا & 9 & .78 & 4.4 & تدريب الطلبة على نمط اسئلة الاختبار ات الوطنية. & 8 \\
\hline كبيرة جدأ & & .60 & 4.6 & المجال الثاني : طرق العلاج & \\
\hline
\end{tabular}

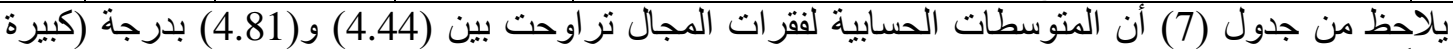

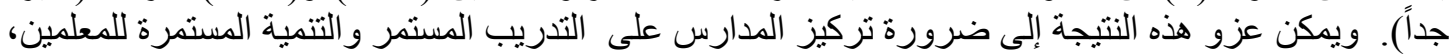

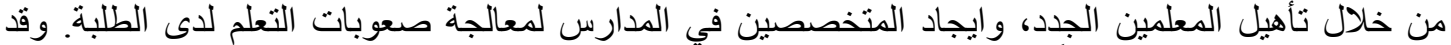

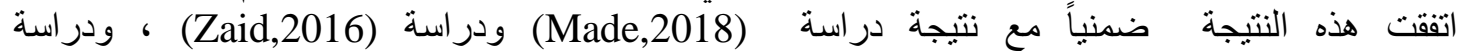
(Jabaeb,2010) . (al-mosawe,2009)

\section{التوصيات: في ضو نتائج الدراسة فقد اوصت الباحثة بما يلي:} - - التدريب المستمر للمعلمين على استخدام طر ائق التدريس الحديثة.

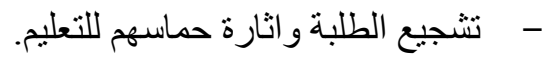

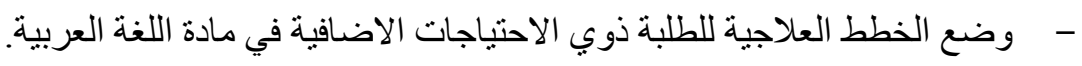
- - إنر الك المعلمين في وضع المناهج الدراسية . 


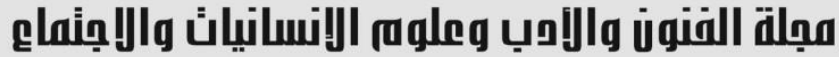

Journal of Arts, Literature, Humanities and Social Sciences www.jalhss.com

1. ابن جني ، أبو الفتح .(1955). الخصائص ج/143/ص/33 عالم الكتب تح/ محمد علي النجار. 2.

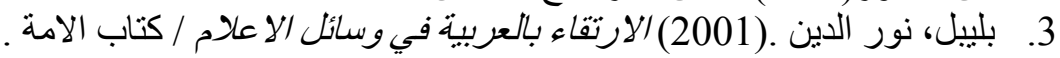

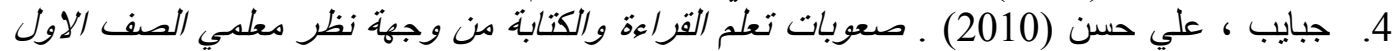

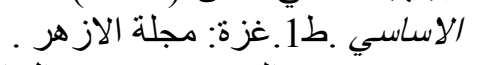

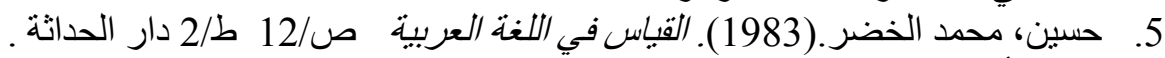

6. عمر، أحمد مختار عبد الحميد.(2008) معجم اللغة العربية المعاصرة طاسية 1/2. بمساعدة فريق عمل النانشر: عالم الكتب. 7. 8. النصار، صالح (2012)، ضعف ألطلبة في اللغة العربية، بيروت ـ لبنان: المؤتمر الدولي للغة العربية،

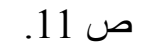

9. عبد الرازق ،عبد الرحمن (2010) ، أسباب تلني مستوى التحصيل في مادة اللغة العربية...، عمان:

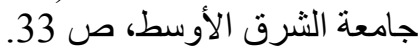
10. زيد، ميرا محمد رمضان (2016) رسالة ماجستير بعنوان اسباب تندي مسنوى القراءة ومقترحات

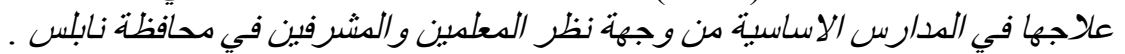

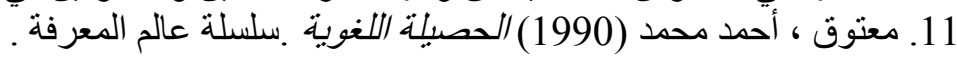

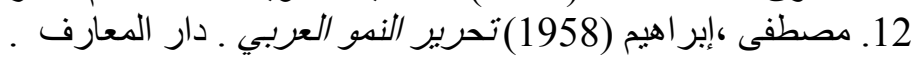

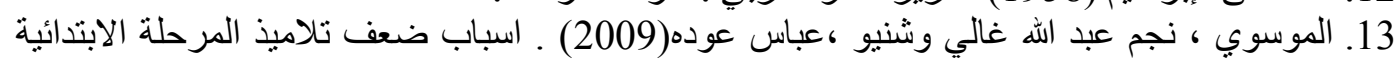
في مادة القراءة من وجهة نظر معلمي المادة ـ القاهرة ، دار الثقافة للنشر و التنوزيع.

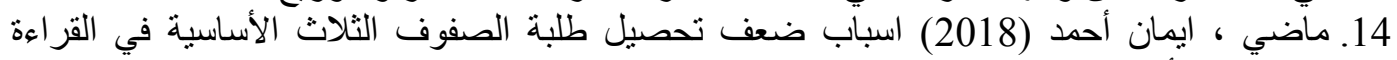
و الكتابة / الأردن ، مجلة العلوم التربوية والنفسية ،عان 11، مج2. 15. موقع وزارة التربية و التعليم الاردنية ( www.moe.gov.jo ) 


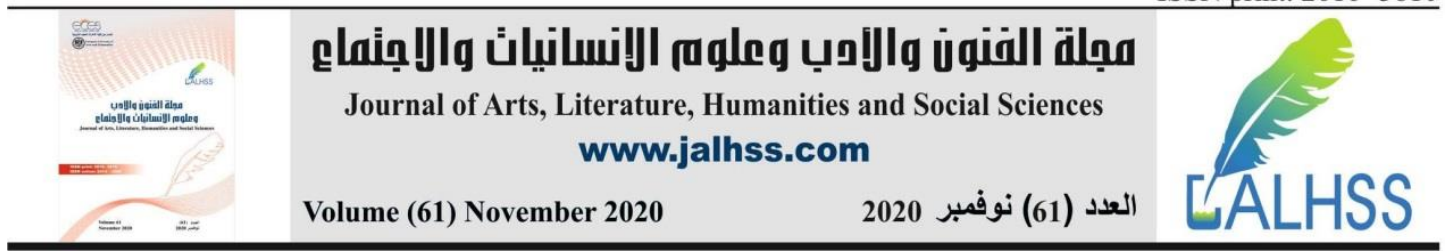

\section{References}

\section{-The holy Quran}

\section{-The noble Prophets Sunnah}

1. -Abd Al-razzak,Abd Al-rahman(2010), Reasons for the low level of achievement in the Arabic language course..., Amman:Middel East University,P/33

2. Amaireh,Khaleel Ahmed.(1987)In linguistic analysis Al-manar library E/1-

3. -Al-nassar,Saleh(2012), The weakness of students in the Arabic language,Beirut,Lebanon:International Conference on the Arabic language P/11

4. -Al-mosawe,Najem Abd Al-lah Ghaly washenyo,Abas Odeh(2009) .Reasons for the weakness of primary school pupils in reading material from the viewpoint of the subject teachers.Cairo,House of culture for publishing and distribution

5. Blebel,Noor Al-deen.(2001)Upgrading Arabic in the media / The nation book-

6. -Husain,Mohamed Al-khader.(1983).Measurement in the Arabic language P/12 E/2 Al-hadatha house

7. -Ibn Jnne, Abu Al-fateh,(1955).Properties P/1 P/1 The world of books/Mohamed Ali Al-najar

8. -Ibn Mandor $(711 \mathrm{H})$.Arabes tong P/1 P/143

9. -Jabayeb,Ali Hasn(2010) .Difficulties in learning to read and write from the viewpoint of first grade teachers

10. Jordanian Ministry of Education website ( www.moe.gov.jo ) -

11. -Mostafa,Ibraheem(1958),Freeing arab growth, Al-ma`aref house

12. Ma`atok,Ahmed Mohamed(1990),Linguistic outcome,Knowledge world series-

13. -Mady,Eman Ahmed (2018), Reasons for poor achievement of the three basic classes in reading and writing/Jordan,Journal of educational and psychological sciences , N/11.Jo/2

14. -Omar,Ahmed Mokhtar Abd Al-hameed.(2008)A Dictionary of contemporary Arabic language E/1.With a help of Al-nnas team:The world of books

15. -Zaid,Mera Mohamed Ramadan(2016),Master thesis entitled Reasons for the low level of reading and writing and proposals for treatment in basic schools from the viewpoint of teachers and supervisors in Nablus Governorate 